This document is confidential and is proprietary to the American Chemical Society and its authors. Do not copy or disclose without written permission. If you have received this item in error, notify the sender and delete all copies.

\title{
Surface Science Investigations of Icy Mantle Growth on Interstellar Dust Grains in Cooling Environments
}

\begin{tabular}{|r|l|}
\hline Journal: & ACS Earth and Space Chemistry \\
\hline Manuscript ID & sp-2019-00052v.R1 \\
\hline Manuscript Type: & Article \\
\hline Dute Submitted by the & n/a \\
\hline Complete List of Authors: & $\begin{array}{l}\text { Marchione, Demian; Heriot-Watt University School of Engineering and } \\
\text { Physical Sciences, Institute of Chemical Sciences, } \\
\text { Rosu-Finsen, Alexander; University College London Department of } \\
\text { Chemistry } \\
\text { Taj, Skandar; Heriot Watt University } \\
\text { Lasne, Jerome; IMT Lille Douai, SAGE } \\
\text { Abdulgalil, Ali; Heriot-Watt University School of Engineering and Physical } \\
\text { Sciences } \\
\text { Thrower, John; Aarhus Universitet, Department of Physics and } \\
\text { Astronomy } \\
\text { Frankland, Victoria; University of Surrey } \\
\text { Collings, Mark; Heriot-Watt University School of Engineering and Physical } \\
\text { Sciences } \\
\text { McCoustra, Martin; Heriot-Watt University, Institute of Chemical } \\
\text { Sciences }\end{array}$ \\
\hline
\end{tabular}

\section{SCHOLARONE ${ }^{\text {TH }}$ Manuscripts}




\title{
Surface Science Investigations of Icy Mantle Growth on Interstellar Dust Grains in Cooling Environments
}

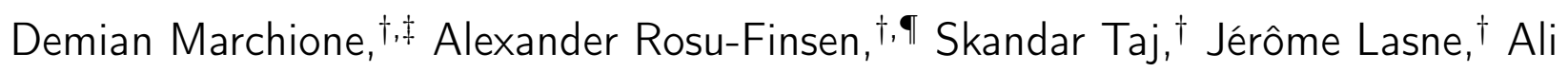 \\ G. M. Abdulgalil, ${ }^{\dagger}$ John D. Thrower, ${ }^{\dagger}, \S$ Victoria L. Frankland, ${ }^{\dagger}, \|$ Mark P. \\ Collings, ${ }^{\dagger}$ and Martin R. S. McCoustra*, ${ }^{\dagger}$ \\ $\dagger$ Institute of Chemical Sciences, Heriot-Watt University, Riccarton, Edinburgh, EH14 4AS, \\ $U K$ \\ $\ddagger$ Current address: Dipartimento di Chimica, Biologia e Biotecnologie, Università degli \\ Studi di Perugia, 06123 Perugia, IT \\ \Current address: Department of Chemistry, Christopher Ingold Building, University \\ College London, London, WC1H OAJ, UK \\ $\S$ Current address: Department of Physics \& Astronomy, Aarhus University, Aarhus, 8000 \\ $D K$ \\ ||Current address: Department of Chemistry, Faculty of Engineering and Physical Sciences, \\ University of Surrey, 388 Stag Hill, Guildford, GU2 7XH, UK \\ E-mail: m.r.s.mccoustra@hw.ac.uk
}

\begin{abstract}
Experimental measurements on the thermal and non-thermal behaviour of water and other simple molecules, including organic compounds such as methanol and benzene, on model interstellar dust grain surfaces and on solid water surfaces using surface science


techniques and methodologies are reviewed. A simple qualitative model of the early stages mantle growth arising from a synthesis of the results of such investigations from our own laboratory and others is presented.

\section{Keywords}

Icy grains, molecular clouds, thermal desorption, diffusion, non-thermal desorption, electroninduced chemistry, water ice

\section{Introduction}

As a dust grain journeys from a diffuse to a dense interstellar environment, the temperature drops as the density of the local environment increases. As this proceeds, water $\left(\mathrm{H}_{2} \mathrm{O}\right)$ reactively accretes from its constituent atomic components and assuming a low enough temperature, $\mathrm{H}_{2} \mathrm{O}$ is accommodated on the surface. To date, $\mathrm{H}_{2} \mathrm{O}$ in the ISM is known to be formed via three types of reactions: ${ }^{1-5}$ 1) ion-neutral reactions, that dominate at low temperatures and proceed with no activation barrier, 2) neutral-neutral (radical) reactions, that are known to dominate around room temperature and above, and 3) solid state (grain catalysed) chemistry lowering significantly the activation barrier for the radical reactivity allowing a rich chemistry even at low temperatures. It is interesting to note that for the chemistry occurring on the surface of the interstellar grains, many reactive pathways proceed via $\mathrm{H}_{2} \mathrm{O}_{2}$ formation that is then readily converted in $\mathrm{OH}$ and $\mathrm{H}_{2} \mathrm{O}$. Moreover, several of the reactions that convert the adsorbed $\mathrm{O}$ to $\mathrm{OH}, \mathrm{H}_{2} \mathrm{O}$ and $\mathrm{O}_{2}$ on dust can result in their direct release into the gas phase. Here, these species can further react or be re-adsorbed on the grain surface. An interesting question to ask is; how does $\mathrm{H}_{2} \mathrm{O}$ behave once adsorbed on a dust grain surface? Temperature-programmed desorption (TPD) experiments are able to answer part of this question as TPD probes the interactions between adsorbates and surfaces and between the adsorbed molecules themselves. TPD experiments ${ }^{6-8}$ of sub-monolayer and 
Laboratory measurements such as those reported and referenced in this work can significantly improve our understanding of astrochemical phenomena such as icy mantle accretion on interstellar grains in diffuse, translucent and dense clouds. However, the impact of such findings must be properly assessed via elaborate theoretical models in order to extrapolate their implications to astrophysical contexts. As part of this process astrophysical modellers have turned to simulating laboratory experiments as a step towards more realistic and accurate models of astrophysical environments and processes. For instance, the first off-lattice Monte Carlo kinetics model of interstellar dust grain surface chemistry presented by Gar- 
$\operatorname{rod}^{11}$ was initially constructed $a b$ initio with no emphasis on laboratory data. However, a subsequent version of the model was tuned to reproduce certain key experimental values before extrapolation to conditions appropriate to proto-planetary disks. ${ }^{12}$ Further examples of this approach can be found in the literature. The large scale Monte Carlo model of Vasyunin and Herbst, ${ }^{13}$ describing both gas-phase chemistry and the chemistry occurring in the icy mantles of interstellar grains, accurately describes the desorption behaviour of the icy mantle during the warm-up phase due to a close comparison and adjustment with laboratory TPD data of ice desorption. Another noteworthy case where simulations and experiments work hand in hand is the work of Karssemeijer et al. ${ }^{14}$ investigating the dynamics of CO in amorphous solid water (ASW). Particularly, the coverage dependence of the binding energy at sub-monolayer level that was previously extracted from TPD data ${ }^{15}$ is well reproduced by the simulations; and the energy barrier for diffusion is determined from both the simulations and the isothermal desorption experiments. The binding energy of volatile molecules $\left(\mathrm{N}_{2}\right.$, $\left.\mathrm{CO}, \mathrm{CO}_{2}, \mathrm{O}_{2}, \mathrm{CH}_{4}\right)$ on $\mathrm{ASW}$ and of $\mathrm{NH}_{3}$ on crystalline water ice have been measured in the laboratory. ${ }^{16,17}$ The authors found that for most of these species the binding energies decrease with increasing coverage in the sub-monolayer regime and obtained values much larger than commonly used in gas-grain models. When the newly determined binding energy distributions are used in a simulation of gas-grain chemistry for cold cloud and hot-core models, the authors found that a fraction of the volatiles remain adsorbed on the grain surface to higher temperatures compared to other astrochemical models. These and other works ${ }^{18-21}$ provide large scale astrochemical modellers with important input parameters that would otherwise be overlooked.

Obviously, simulations have given us deep insight into the mantle accretion ${ }^{13,22}$ and the methodologies employed are not the object of debate in this paper. Nevertheless, recent experimental findings show that there is still ample room for improvement in such simulations. The work of Dulieu and colleagues, ${ }^{23,24}$ for example, highlighted the effect of a small 


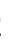

difference in affinity between a certain species and a surface with respect to a second species on the same substrate during their co-deposition. At sub-monolayer levels, $\mathrm{CO}$ binds more strongly to water ice than $\mathrm{N}_{2}$ and $\mathrm{O}_{2}$ and hence $\mathrm{CO}$ displaces these two species from the most stable adsorption sites via a segregation mechanism. This means that both $\mathrm{N}_{2}$ and $\mathrm{O}_{2}$ will thermally desorb at lower temperatures when mixed with $\mathrm{CO}$ on solid water than when deposited as pure substances.

Our work can be contextualised within this framework, as we aim to highlight recent laboratory findings from our group and others that challenge our current picture of the icy mantle of the interstellar grains and can potentially improve the accuracy in prediction of large scale astrochemical models. We will specifically report on (1) thermal desorption and the impact of surface heterogeneity; (2) diffusion of $\mathrm{H}_{2} \mathrm{O}$ on silica surface as probed by infrared spectroscopy; non-thermal desorption of small molecules through (3) photon absorption and (4) radiolytic interaction; and (5) efficient $\mathrm{H}_{2}$ generation from ionisation of saturated C-containing species. Finally we will present a simple model to highlight how laboratory experimental findings can challenge and further our understanding of the interstellar icy grain structure and pave the route to future key experiments.

\section{Experimental}

The experimental apparatus, ancillary equipment and general methods employed have been described in detail previously. ${ }^{25-29}$ Herein only details specific to the reported measurements are given. Gas doses are reported in Langmuir units $\left(1 \mathrm{~L}=10^{-6}\right.$ Torr s). These can be used to estimate the film thickness, $d$, from Eq. 1 based on the assumption of uniform film growth:

$$
\begin{gathered}
d=\frac{S P t}{\sqrt{2 \pi m k_{B} T}} \frac{1}{\rho_{s}}=\frac{Z_{W} t}{\rho_{s}} \\
5 \\
\text { ACS Paragon Plus Environment }
\end{gathered}
$$


where $S$ is the sticking coefficient (assumed to be 1), $P$ is the pressure recorded on the hot cathode ion gauge corrected for the molecular ionisation efficiencies, $t$ is the time of exposure, $k_{B}$ is the Boltzmann constant, $T$ is the temperature of the dosed molecules, $Z_{W}$ is the bombardment rate (the incident flux), $\rho_{S}$ is the molecular volume density and $m$ is the molecular mass. In Eq. 1, we first define the number of molecules deposited onto the substrate $\left(N_{t o t}\right.$, molecules per unit of surface area) during the dose $\left(N_{t o t}=Z_{W} t\right)$ and then divide this by the density (molecules per unit of volume).

The results reported in Section 3 are from experiments conducted in two ultrahigh vacuum (UHV) chambers, both are shown in Figure1. The first UHV system (Figure 1 panel 1) is capable of reaching pressures of $2 \times 10^{-10}$ mbar pumped by a liquid nitrogen trapped 6 " diffusion pump backed by a rotary pump. The sample is an oxygen free high conductivity (OFHC) copper block coated with an amorphous silica $\left(\mathrm{aSiO}_{2}\right)$ layer $(c a .300 \mathrm{~nm}$ thick) deposited by electron beam evaporation as described by Thrower et al. ${ }^{25}$ resulting in a very rough surface with peak-trough variations of up to $c a$. $60 \mathrm{~nm}$. This sample is mounted on the end of a closed-cycle helium-cooled cold finger with a base temperature of 15 - 20 K. A cartridge heater (Heatwave Labs Inc.) placed inside the copper block is used to uniformly heat the $\mathrm{aSiO}_{2}$ surface. The surface and cold finger temperatures are monitored using KP-type (Au-Chromel) thermocouples connected to IJ-6 temperature controllers. The UHV chamber is equipped with a pulse-counting quadrupole mass spectrometer (QMS, Hiden Analytical Ltd, HAL301), residual gas analyser mass spectrometer (RGA, SRS 200) and reflection-adsorption infrared spectroscopy (RAIRS, Varian 670-IR FTIR spectrometer) apparatus. Also attached to the main chamber are two doubly differentially pumped atomic beam chambers. Each of these chambers is split into plasma and beam chambers by an internal wall fitted with a $5 \mathrm{~mm}$ collimator flange. The base pressure in the plasma chambers routinely reaches below $5 \times 10^{-10}$ mbar when the beams are not in use. Each plasma cham- 
1)

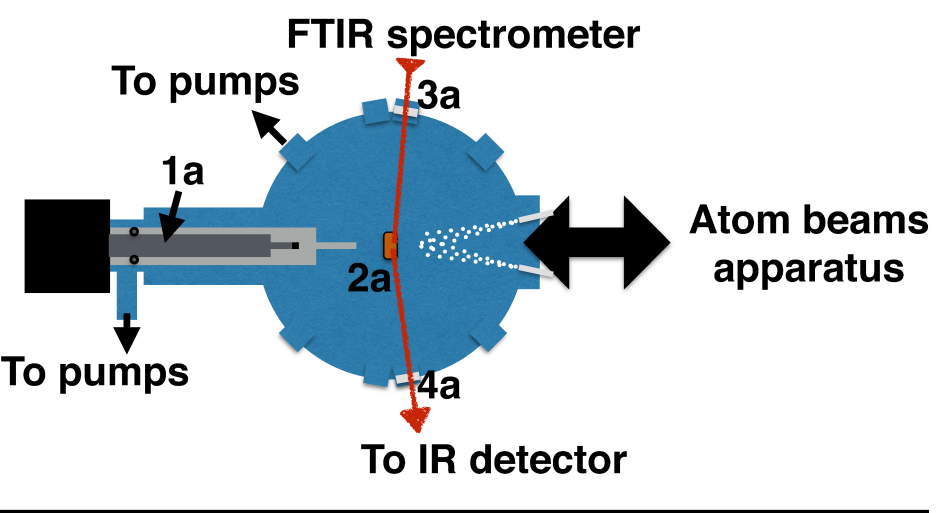

2)

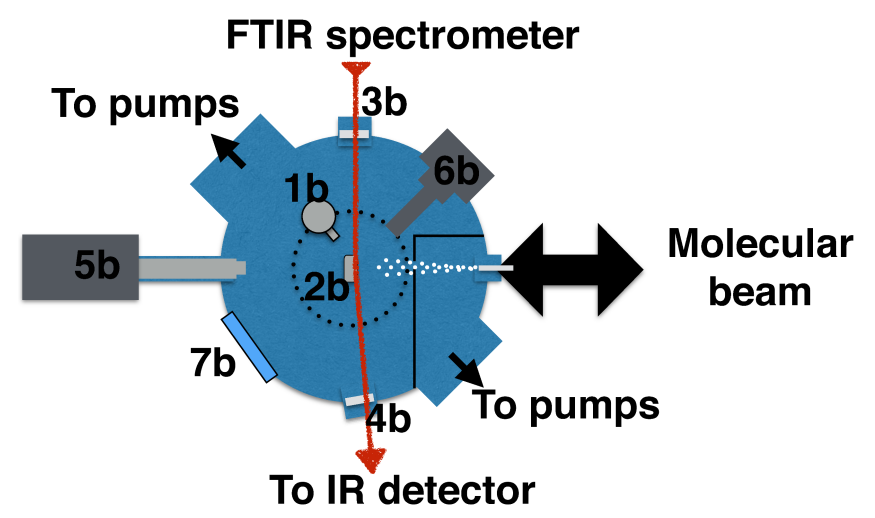

Figure 1: Schematic of the UHV chambers used for the experiments conducted at HeriotWatt University. Panel 1 shows the Ice Rig used for the experiments reported in Section 3.2. Labels in this panel are: 1a - quadrupole mass spectrometer; 2a - Sample mount with substrate; $3 \mathrm{a}$ and $4 \mathrm{a}-\mathrm{KBr}$ windows for IR spectroscopy. Panel 2 shows the Beam Rig used for the electron irradiation experiments described in Sections 3.4 and 3.5. Labels in this panel are: $1 \mathrm{~b}$ - rotating quadrupole mass spectrometer; $2 \mathrm{~b}$ - Sample mount with substrate; $3 \mathrm{~b}$ and $4 \mathrm{~b}-\mathrm{KBr}$ windows for IR spectroscopy; $5 \mathrm{~b}$ - Residual gas analyser; $6 \mathrm{~b}$ - electron gun; $7 \mathrm{~b}$ - viewport. Both set-ups have two levels where the sample can be located by adjusting its height. Only the level where the experiments were conducted is displayed for the two chambers in the panels. The other level is not shown for clarity, but it is worthwhile noting that it is equipped with viewports to allow visual access to the chamber and with leak valves for background dosing. 
ber is equipped with a radio frequency $(\mathrm{RF})$ powered plasma source (Oxford Scientific, $\mathrm{RF}$ OSPrey) and a fibre optic spectrometer (Ocean Optics, USB4000). Molecular beam modulation spectrometry (MBMS) analysis can be performed allowing the identity and intensity of gaseous species during the beam irradiation part of an experiment to be obtained. Although most of these species would be from the beam or background contaminants, other species may be detected that were formed through surface reactions and desorbed upon formation. As a consequence, this technique provides more detailed kinetic data of the processes occurring on the surface that would otherwise be missed using other analytical techniques. TPD measurements can also be performed using the QMS. An alternate method for introducing molecules is through background deposition of gases and liquids using designated and differentially pumped glass gas handling lines.

The substrate used in the UHV chamber (Figure 1 panel 2) for electron irradiation experiments was a polished stainless steel disc coated with ca. $200 \mathrm{~nm} \mathrm{aSiO}$ deposited $^{2}$ by electron beam evaporation. ${ }^{25}$ The substrate was cooled through contact with a liquid nitrogen reservoir, reaching a base temperature of $112 \pm 2 \mathrm{~K}$ as measured by a K-type thermocouple spot-welded to the edge of the stainless steel disc. Layered ices were obtained by sequential background deposition using benzene $\left(\mathrm{C}_{6} \mathrm{H}_{6}\right.$; Fluka, 99.5\%), de-ionised water $\left(\mathrm{H}_{2} \mathrm{O}\right)$, methanol $\left(\mathrm{CH}_{3} \mathrm{OH}\right)$ (Sigma-Aldrich, HPLC grade 99.9\% pure), or diethyl ether $\left(\mathrm{CH}_{3} \mathrm{CH}_{2} \mathrm{OCH}_{2} \mathrm{CH}_{3}\right.$, Sigma-Aldrich, Chromasolv grade $99.9 \%$ pure). All the chemicals were stored in glass vials and purified by repeated freeze-pump-thaw cycles before use. Crosscontamination was avoided by collecting the vapour phase from the liquids using two independent manifolds each interfaced to its own dedicated leak valve (Vacuum Generators MD95).

Sample irradiation was performed using an electron gun (Kimball Physics, ELG-2) incident at $c a .30^{\circ}$ with respect to the substrate normal with a $1 \mathrm{~mm}^{2}$ beam spot size. Desorption 
Electron trajectories in the investigated ices were calculated via Monte Carlo simulations consistent with the experimental conditions and were published elsewhere. ${ }^{28,29}$ The results indicate that the calculated penetration depth of $250 \mathrm{eV}$ primary electrons has a maximum around the uppermost $5 \mathrm{~nm}$ of the ices. Thus, all the binary layered systems reported here have an overall thickness larger than the primary electron maximum penetration depth. The sole exception was found for the thinnest ice $\left(70 \mathrm{~L} \mathrm{H}_{2} \mathrm{O}\right.$ topped with $5 \mathrm{~L}$ of $\mathrm{C}_{6} \mathrm{H}_{6}$, ca. $8 \mathrm{~nm}$ thick), although the fraction of primary electrons reaching the substrate remains negligible. ${ }^{28,29}$

\section{Results and discussion}

\subsection{Thermal Desorption by Temperature-Programmed Desorption}

TPD has been widely used over the last two decades to determine the binding energies of molecules on grain surfaces; ${ }^{30}$ a crucial input to our understanding of the gas-grain interaction in the interstellar medium. For the most part, simple analyses are presented in the literature for desorption of ultrathin solid films of pure mantle components assuming zero order kinetics or for sub-monolayer quantities of adsorbed mantle components on model 
grain surfaces (e.g. silica, graphite or water ice films) assuming first order kinetics. Such studies typically report a single binding energy and, sometimes, the pre-exponential factor for desorption. However, such analysis is inaccurate especially where the surface from which the molecules desorb is heterogeneous, as multiple binding sites result in a range of binding energies. Kay and co-workers were the first to report a simple inversion analysis which advanced the interpretation of sub-monolayer desorption data on grains. ${ }^{31}$ Work by Dulieu, Lemaire, Kay, McCoustra, Vidali, and Zacharias illustrates this procedure. ${ }^{23,32-36}$ Table 1 summarises this state-of-the-art in TPD.

Table 1: Binding energy ranges of small molecule on silica, graphite and water surfaces obtained from TPD data. Values for water ice on $\mathrm{Au}$, sapphire, $\mathrm{Ru} / \mathrm{Al}, \mathrm{Al}_{2} \mathrm{O}_{3}$ surfaces have also been reported. Note that n.a. stands for not available.

\begin{tabular}{|c|c|c|c|c|}
\hline \multirow[t]{2}{*}{ Species } & \multirow[t]{2}{*}{ Surface } & \multicolumn{2}{|c|}{ Binding Energy / kJ mol ${ }^{-1}$} & \multirow[t]{2}{*}{ Reference } \\
\hline & & Sub-monolayer & Multilayer & \\
\hline \multirow{5}{*}{$\mathrm{H}_{2} \mathrm{O}$} & $\mathrm{aSiO}_{2}$ & n.a. & $49.3 \pm 2$ & 37 \\
\hline & Graphene & n.a. & $46.0 \pm 3$ & 38 \\
\hline & $\mathrm{Au}$ & n.a. & $46.6-48.0$ & 6 \\
\hline & Sapphire & n.a & $49.4 \pm 0.8$ & 7 \\
\hline & $\mathrm{Ru} / \mathrm{Al}, \mathrm{Al}_{2} \mathrm{O}_{3}$ & n.a. & $46.9-48.3$ & 8 \\
\hline \multirow{3}{*}{$\mathrm{CO}$} & $\mathrm{H}_{2} \mathrm{O}$ & $9.6 \pm 0.5$ & n.a. & 15 \\
\hline & $\mathrm{aSiO}_{2}$ & $7.2-12.2$ & $6.9-7.3$ & $15,37,39,40$ \\
\hline & Graphene & $7.6-12.5$ & $7.6 \pm 0.4$ & 41 \\
\hline \multirow{3}{*}{$\mathrm{N}_{2}$} & $\mathrm{H}_{2} \mathrm{O}$ & $9.6 \pm 0.5$ & n.a. & 41 \\
\hline & $\mathrm{aSiO}_{2}$ & $8.8-13.4$ & $6.6-6.9$ & 37,39 \\
\hline & Graphene & $6.5-11.2$ & $7.2 \pm 0.4$ & 41 \\
\hline \multirow{3}{*}{$\mathrm{O}_{2}$} & $\mathrm{H}_{2} \mathrm{O}$ & $7.6-9.7$ & $7.5-7.8$ & 15 \\
\hline & $\mathrm{aSiO}_{2}$ & $7.7-8-11.9$ & 7.4-7.6 & $15,37,39,40$ \\
\hline & Graphene & $8.6-11.8$ & $8.6 \pm 0.4$ & 41 \\
\hline \multirow{3}{*}{$\mathrm{CH}_{4}$} & $\mathrm{H}_{2} \mathrm{O}$ & $11.4 \pm 0.6$ & $10.5 \pm 0.5$ & 41 \\
\hline & $\mathrm{aSiO}_{2}$ & n.a & n.a. & \\
\hline & Graphene & $10.5-14.9$ & $9.9 \pm 0.5$ & 41 \\
\hline \multirow{3}{*}{$\mathrm{CO}_{2}$} & $\mathrm{H}_{2} \mathrm{O}$ & $18.3-21.0$ & $18.8-19.6 \quad 15,42$ & \\
\hline & $\mathrm{aSiO}_{2}$ & $18.9-25.0$ & $18.7 \pm 0.7$ & 15 \\
\hline & Graphene & $19.8 \pm 2.9$ & $23.0-24.8$ & 38,42 \\
\hline
\end{tabular}

Typically, this analysis starts by direct inversion of the Polanyi-Wigner Equation, Eq. 2: 


$$
r_{d e s}=\frac{\mathrm{d} N_{a d s}(t)}{\mathrm{d} t}=N_{a d s}(t)^{n} \nu e^{-\frac{E_{d e s}}{k_{B} T}}
$$

where $r_{d e s}$ is the desorption rate (which is equivalent to the rate of change of surface concentration, $\left.N_{a d s}\right), \nu$ is the pre-exponential factor, $n$ and $E_{\text {des }}$ are the desorption order and energy respectively, $k_{B}$ is the Boltzmann constant and $T$ is the surface temperature. Rearranging Eq. 2 yields Eq. 3:

$$
E_{\text {des }}\left(N_{a d s}(t)\right)=-k_{B} T \ln \left(\frac{r_{d e s}}{\nu N_{a d s}(t)^{n}}\right)
$$

$N_{a d s}(t)$ can be determined from an estimate of the total number of molecules, $N_{\text {tot }}$, adsorbed on the surface as discussed for Eq. 1. Knowing this, the TPD data can be normalised since also the integral of the TPD curve up to a certain time is the number of desorbed molecules up to that time value. Subsequently, the variation of $E_{d e s}$ with respect to $N_{a d s}$ can be used to yield the probability of finding a particular desorption energy $\left(P\left(E_{\text {des }}\right)\right)$ (Eq. 4$)$ :

$$
\left(P\left(E_{d e s}\right)\right)=-\frac{\mathrm{d} N_{a d s}}{\mathrm{~d} E_{d e s}}
$$

Even this methodology is limited by the assumption that the pre-exponential factor is fixed at $10^{12} \mathrm{~s}^{-1}$ (for a physisorption interaction) or $10^{13} \mathrm{~s}^{-1}$ (for chemisorption). Recent work by Kay and co-workers ${ }^{43,44}$ has revealed the weakness of this assumption that goes back to the classical Redhead analysis ${ }^{45}$ and can be attributed to an over-simplification of the transition state theory description of desorption which neglects transition state rotational motion. This more recent and complete analysis suggests a pre-exponential factor of around $10^{17} \mathrm{~s}^{-1}$ for $\mathrm{C}_{6} \mathrm{H}_{6}$ desorbing from graphene using their optimised inversion procedure. ${ }^{44}$

The impact of surface heterogeneity can also be seen in the vibrational spectroscopy of simple molecules on model grain surfaces in the broadening of the spectral features. This is nicely illustrated in the study of Taj et $a l .{ }^{46}$ on the line profiles of sub-monolayer quantities 
of $\mathrm{CO}$ on $\mathrm{aSiO}_{2}$ and porous amorphous solid water (p-ASW) ice, which explored the impact of surface heterogeneity on the frequency of the $\mathrm{CO}$ vibration assuming broad distributions of $\mathrm{CO}$ binding sites on these surfaces. The authors also investigated the $\mathrm{CO}$ deposition mechanism in considering both ballistic deposition, where a species is unable to diffuse once adsorbed and diffusive deposition, where species can diffuse across the substrate. Through comparison with experimental IR spectra, this work showed the propensity of CO to diffuse on $\mathrm{aSiO}_{2}$. For $\mathrm{CO}$ on $\mathrm{p}-\mathrm{ASW}$, the interpretation is less clear as both the diffusive and ballistic models appear to fit the observed IR CO line shape.

\subsection{Surface Diffusion probed by RAIRS}

As $\mathrm{H}_{2} \mathrm{O}$ is generally the most abundant component of the solid state materials on interstellar dust grains, desorption of multilayer $\mathrm{H}_{2} \mathrm{O}$ has been studied on surfaces ranging from sapphire to polycrystalline and single crystal metals ${ }^{6,8,47}$ including dust grain mimics such as $\mathrm{aSiO}_{2}{ }^{37}$ and graphene. ${ }^{43}$ Many of these studies report zero, or near-zero, order desorption for all $\mathrm{H}_{2} \mathrm{O}$ coverages. As zero order desorption kinetics is associated with multilayer desorption, this indicates that $\mathrm{H}_{2} \mathrm{O}$ molecules must diffuse and agglomerate into clusters and islands on the surface before or during the desorption. This also implies that the $\mathrm{H}_{2} \mathrm{O}-\mathrm{H}_{2} \mathrm{O}$ interaction is stronger than the $\mathrm{H}_{2} \mathrm{O}$-substrate interaction. Experimentally, $\mathrm{H}_{2} \mathrm{O}$ molecules at sub-monolayer coverages have been shown to be mobile on model dust grain surfaces at temperatures as low as $17 \mathrm{~K}{ }^{48}$ exhibiting an activation energy for diffusion of about $2 \mathrm{~kJ}$ $\mathrm{mol}^{-1}$.

The data in Figure 2 are illustrative of the de-wetting and agglomeration experiments of $\mathrm{H}_{2} \mathrm{O}$ on $\mathrm{aSiO}_{2}$ obtained using reflection-absorption infrared (RAIR) spectra of the $\nu \mathrm{OH}$ stretching vibration. ${ }^{48}$ This figure shows how the intensity of the $\nu \mathrm{OH}$ stretching band increases over a period of 5 hours at a temperature of $18 \mathrm{~K}$ before a final annealing to $100 \mathrm{~K}$ for 20 minutes producing a fixed "infinite time" spectrum. The peak is constant in 
Figure 2: RAIR Spectra of the $\mathrm{OH}$ stretching region of a sub-monolayer quantity of $\mathrm{H}_{2} \mathrm{O}$ deposited on $\mathrm{aSiO}_{2}$ at $17 \mathrm{~K}$ and warmed for the indicated times to $18 \mathrm{~K}$. The infinite time corresponds to annealing for 20 minutes at $100 \mathrm{~K}$. Reproduced from reference 48 with permission from the PCCP Owner Societies.

position and the dangling $\mathrm{O}-\mathrm{H}$ modes cannot be clearly observed. Shifts in $\nu \mathrm{OH}$ are known to occur in particle growth up to diameters of $4 \mathrm{~nm} .{ }^{49}$ The absence of such shifts in Figure 2 would suggest that this initial growth phase is complete before our first measurement is made. In addition, the presence of heavy spectral contamination by gas phase water rovibrational bands from our instrument purge gas will make observation of the dangling bonds difficult. This is not uncommon in studies of $\mathrm{H}_{2} \mathrm{O}$ ice. Control experiments conducted under the same conditions, where the partial pressure of $\mathrm{H}_{2} \mathrm{O}$ in the UHV chamber was significantly less than $10^{-13}$ mbar, indicated negligible $\mathrm{H}_{2} \mathrm{O}$ film growth. Consequently, the only explanation for the increase in $\nu \mathrm{OH}$ intensity is an increase in the oscillator strength of the band. Formation of hydrogen-bonds (of the type $\mathrm{H} \cdots \mathrm{O}-\mathrm{H}$ ) is known to increase the $\nu \mathrm{OH}$ oscillator strength. ${ }^{49}$ Thus, $\mathrm{H}_{2} \mathrm{O}$ must be diffusing over the $\mathrm{aSiO}_{2}$ and highly oriented pyrolytic graphite (HOPG) surfaces to form hydrogen-bonded clusters that eventually desorb following zero order kinetics. Assuming first order kinetics, the rate constant for this dewetting process can be calculated from data such as those presented in Figure 2. Table 2 summarises the rate constants for this agglomeration process on both surfaces over the range 
of temperatures probed in the experiment.

Table 2: Agglomeration rate constants for $\mathrm{H}_{2} \mathrm{O}$ on the $\mathrm{aSiO}_{2}$ and $\mathrm{HOPG}$ surfaces taken from reference 48 . The numbers in brackets are estimated relative error on the measurements.

\begin{tabular}{lll}
\hline $\mathrm{T}_{\text {anneal }} \pm 0.3 / \mathrm{K}$ & $\mathrm{k}\left(\mathrm{aSiO}_{2}\right) / \mathrm{s}^{-1}$ & $\mathrm{k}(\mathrm{HOPG}) / \mathrm{s}^{-1}$ \\
\hline 17 & $2.432 \times 10^{-5}( \pm 8 \%)$ & - \\
18 & $3.640 \times 10^{-5}( \pm 15 \%)$ & - \\
21 & $5.188 \times 10^{-4}( \pm 14 \%)$ & - \\
24 & $8.894 \times 10^{-4}( \pm 4 \%)$ & $1.488 \times 10^{-3}( \pm 21 \%)$ \\
27 & $8.788 \times 10^{-4}( \pm 9 \%)$ & - \\
29 & - & $1.572 \times 10^{-3}( \pm 1 \%)$ \\
30 & $1.508 \times 10^{-3}( \pm 15 \%)$ & - \\
33 & - & $3.703 \times 10^{-3}( \pm 51 \%)$ \\
40 & $2.046 \times 10^{-3}( \pm 12 \%)$ & - \\
50 & $1.392 \times 10^{-3}( \pm 10 \%)$ & $5.865 \times 10^{-3}( \pm 36 \%)$ \\
60 & $1.300 \times 10^{-3}( \pm 11 \%)$ & - \\
70 & - & $3.289 \times 10^{-3}( \pm 16 \%)$ \\
100 & $1.400 \times 10^{-3}( \pm 27 \%)$ & $4.330 \times 10^{-3}( \pm 51 \%)$ \\
\hline
\end{tabular}

Figure 3 presents the data reported in Table 2 for the $\mathrm{aSiO}_{2}$ surface in the form of an Arrhenius plot. At temperatures below $25 \mathrm{~K}$, there is a $2 \mathrm{~kJ} \mathrm{~mol}^{-1}$ barrier for the agglomeration process, which disappears at temperatures above $25 \mathrm{~K}$. This de-wetting and agglomeration process has been shown to be enhanced by atomic $\mathrm{O}$ bombardment as molecular $\mathrm{O}_{2}$ forms and releases energy (reaction enthalpy). ${ }^{50}$ It is likely that the formation of other molecules would also enhance this process.

Figure 4 shows the results of a simple kinetic simulation in which a sub-monolayer equivalent quantity of gaseous $\mathrm{H}_{2} \mathrm{O}$ randomly adsorbs onto a surface as the surface temperature decreases while the surface presents a barrier to agglomeration as estimated above. Mechanistically, we treat this with the following series of kinetic processes; 


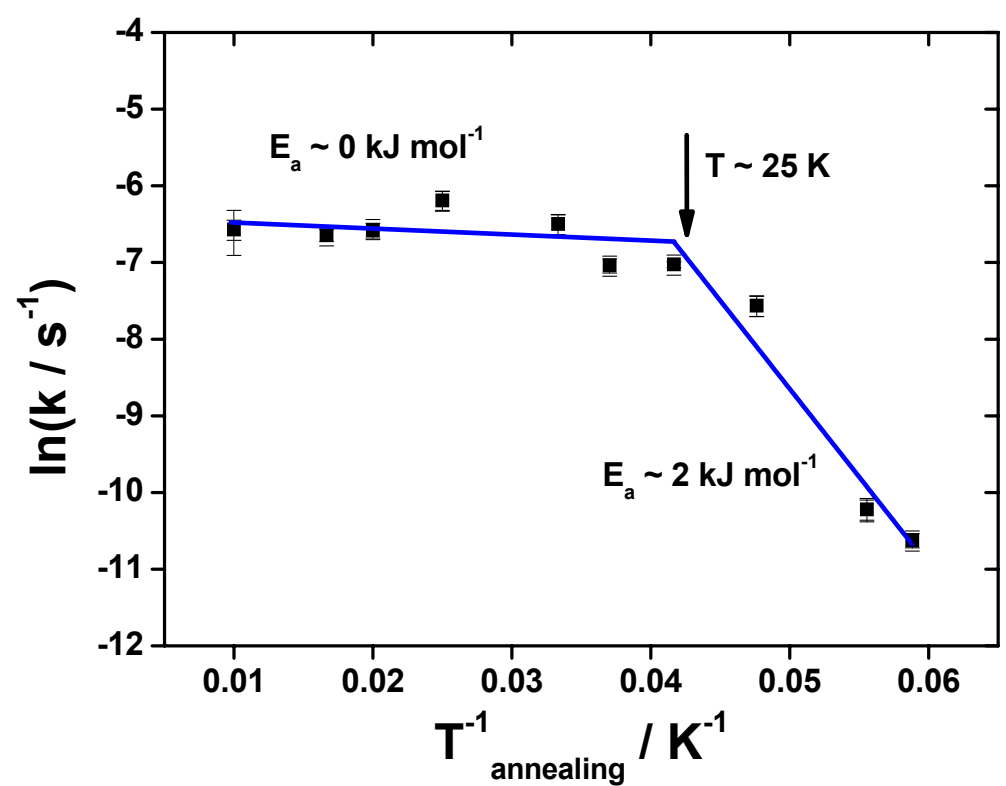

Figure 3: Arrhenius plot of the data in the $\mathrm{aSiO}_{2}$ column in Table 2 illustrating the change in activation barrier for $\mathrm{H}_{2} \mathrm{O}$ agglomeration as the surface temperature changes. Replotted from reference 48 with permission from the PCCP Owner Societies.

$$
\begin{aligned}
& \mathrm{H}_{2} \mathrm{O}(\mathrm{g}) \rightarrow \mathrm{H}_{2} \mathrm{O}(\text { ads }) \\
& \mathrm{H}_{2} \mathrm{O}(\mathrm{c}-\mathrm{ASW}, \mathrm{s}) \rightarrow \mathrm{H}_{2} \mathrm{O}(\mathrm{CSW}, \mathrm{s}) \\
& \mathrm{H}_{2} \mathrm{O} \text { (ads) } \rightarrow \mathrm{H}_{2} \mathrm{O}(\mathrm{CSW}, \mathrm{s}) \\
& \mathrm{H}_{2} \mathrm{O}(\text { ads }) \rightarrow \mathrm{H}_{2} \mathrm{O}(\mathrm{c}-\mathrm{ASW}, \mathrm{s})
\end{aligned}
$$

Adsorption will primarily be to isolated $\mathrm{H}_{2} \mathrm{O}$ molecules, $\mathrm{H}_{2} \mathrm{O}$ (ads), on the substrate surface (Eq. 5a). The model recognises that agglomeration at high temperature will lead to crystallisation and the formation of crystalline solid water (CSW) agglomerates (Eq. 5b and Eq. 5c). At temperatures below $80 \mathrm{~K}, \mathrm{H}_{2} \mathrm{O}$ deposition leading, via agglomeration, to the compact amorphous solid water (c-ASW) particles becomes the dominant channel (Eq. 5d). The simulations also show that the surface concentration of $\mathrm{H}_{2} \mathrm{O}$ (ads) is almost negligible as $\mathrm{H}_{2} \mathrm{O}$ is able to agglomerate on timescales substantially shorter than that of deposition. 


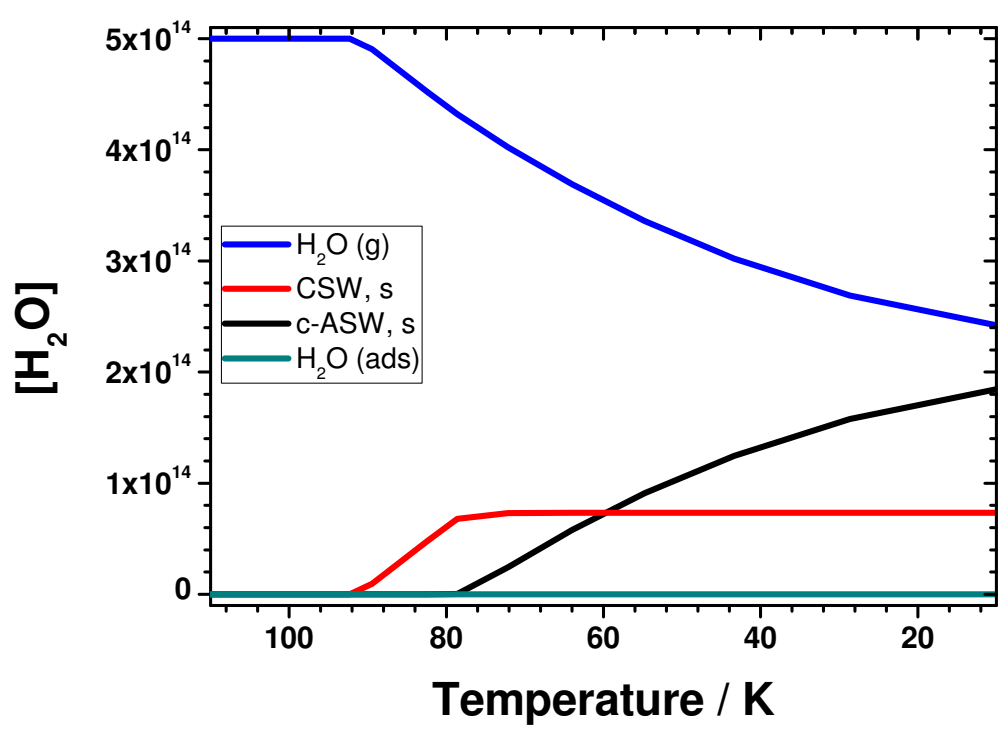

Figure 4: Results of a toy model simulating the deposition of gaseous $\mathrm{H}_{2} \mathrm{O}$ and including diffusive agglomeration on a dust grain surface. The model assumes that agglomeration at high temperature will lead to crystallisation. Reproduced from reference 48 with permission from the PCCP Owner Societies.

With $\mathrm{H}_{2} \mathrm{O}$ de-wetting, the dust grain surface previously covered by $\mathrm{H}_{2} \mathrm{O}$, as in the traditional Onion Model, is now exposed. This creates a duality of environments on interstellar dust on which other molecules can adsorb. As demonstrated, the small binding energy differences between $\mathrm{CO}$ on $\mathrm{aSiO}_{2}$ and ASW result in differential adsorption. ${ }^{46}$ This is equally true of many volatile species, e.g. there is as much as $1 \mathrm{~kJ} \mathrm{~mol}^{-1}$ variation for $\mathrm{O}_{2}$ on different surfaces. ${ }^{15}$ Such alterations in binding energies could result in greater lifetimes of molecules in the solid state, possibly explaining the lack of observable abundances of certain molecular species. For example, $\mathrm{O}_{2}$ lifetimes on a bare dust grain surfaces have been shown to reach values of $10^{9}$ years suggesting that bare grain surfaces may act as a sink for $\mathrm{O}_{2} \cdot{ }^{37} \mathrm{O}_{2}$, incidentally, has also been shown to diffuse across model interstellar surfaces with a diffusion barrier of $2.4 \mathrm{~kJ} \mathrm{~mol}^{-1}{ }^{51}$

Can we see evidence of this behaviour? Observations of $\mathrm{CO}$ in $\mathrm{H}_{2} \mathrm{O}$ poor environments have been shown to produce three features at; $2143.7 \mathrm{~cm}^{-1}, 2139.9 \mathrm{~cm}^{-1}$ and $2136.5 \mathrm{~cm}^{-1} .51$ The first two features were assigned to $\mathrm{CO}$ molecules interacting with other $\mathrm{CO}$ molecules. 
The latter feature at $2136.5 \mathrm{~cm}^{-1}$ was left unassigned. However, this feature compares favourably with laboratory experimental results of $\mathrm{CO}$ adsorbed directly onto $\mathrm{aSiO}_{2}$. Additionally, the invariance of sub-monolayer CO RAIR spectra with deposition temperature leads to the inference that adsorbed $\mathrm{CO}$ is mobile on $\mathrm{aSiO}_{2}$ at cryogenic temperatures. ${ }^{37}$ Diffusion of CO on cold interstellar analogue surfaces is further supported through the line profile simulations reported by Taj et al. ${ }^{46}$ The launch of the James Webb Space Telescope may open additional windows on to this issue.

Experimental and theoretical work from Cuppen and co-workers ${ }^{20,52}$ has shown the propensity for $\mathrm{CO}$ to diffuse on and in $\mathrm{H}_{2} \mathrm{O}$ films while TPD experiments inform us that CO fills all adsorption sites on a surface to form a complete monolayer before building a multilayer. ${ }^{15,37}$ In forming that monolayer, $\mathrm{CO}$ must also diffuse across the surface given the evidence above. This leads us to a picture of the evolving interstellar grain where the grain surface is slowly populated by mountainous $\mathrm{H}_{2} \mathrm{O}$ agglomerates while some parts of the grain surface remains bare. Both the $\mathrm{H}_{2} \mathrm{O}$ and bare grain surfaces are covered by thin films of CO. Hydrogenation of $\mathrm{CO}$ yields methanol, $\mathrm{CH}_{3} \mathrm{OH},{ }^{53,54}$ and methanol, in turn, has been shown to exhibit a preference for those binding sites that lead to a stronger adsorption interaction with the $\mathrm{SiO}_{2}$ surface at low temperature but exhibiting de-wetting and diffusion behaviour at elevated temperatures. ${ }^{55}$

As an aside, the formation of multilayer $\mathrm{CO}$ through diffusion and deposition produces a material that spontaneously exhibits an intense electric field; known as a spontelectric field. ${ }^{56,57}$ This field, and its impact on the magnetic support of the dense medium, have been proposed to play a crucial role in determining the rate of star formation in dense cold, dense environments. ${ }^{58,59}$ 


\subsection{Non-thermal Desorption through Photon-absorption}

It is well established that photo-processes (namely photo-dissociation, photo-ionisation, and photo-desorption) are important to interstellar and circumstellar chemistry. Traditionally, the focus has been on photo-processes driven by vacuum ultraviolet (VUV) radiation as the radiation field near a star is dominated by Lyman- $\alpha(121.6 \mathrm{~nm})$. Even in dense objects, cosmic rays can excite Lyman- $\alpha$ emission via radiolysis of $\mathrm{H}_{2}$. Numerous laboratory investigations have employed microwave-discharge hydrogen-flow lamps (MDHL) in order to simulate the photon-irradiation of astrophysical ices. ${ }^{60-81}$

Such studies have contributed significantly to understanding non-thermal processes in interstellar environments. However, while the MDHL is a realistic radiation source, it does not exclusively emit Lyman- $\alpha$ and contributions to the emission from molecular hydrogen around $160 \mathrm{~nm}$ are observed. ${ }^{82,83}$ Indeed, recent work has demonstrated that the MDHL emission spectrum is actually very sensitive to the operational conditions, especially the intensity ratio of atomic $\mathrm{H}$ to molecular $\mathrm{H}_{2}$ emission. ${ }^{82,83}$ This has led to disagreements between measurements from almost identical experiments employing MDHL by different groups. Measurements on photo-desorption of $\mathrm{CO}$ are the perfect example as $\mathrm{CO}$ photodesorption yields have been reported with values ranging from $3 \times 10^{-3}$ to $6.4 \times 10^{-2} \mathrm{CO}$ molecules per photon. ${ }^{60,61,82,84-87}$

Clearly, the utility of broadband MDHL sources is brought into question unless careful characterisation of the source is performed. Better insight into mechanisms, rates and yields can be obtained using a wavelength-resolved approach. The works led by Bertin ${ }^{88}$ and Fayolle ${ }^{87}$ investigate photo-desorption of $\mathrm{CO}$ with unprecedented detail using monochromatic synchrotron emission in the photon energy range $7-13.6 \mathrm{eV}(117-91 \mathrm{~nm})$ and gas-phase detection of the photo-desorbed CO by QMS. Follow-up studies on other species have allowed generalisation of the main conclusions drawn from the case of $\mathrm{CO}$, which was extensively 
investigated also in mixed ices (e.g. $\mathrm{N}_{2}, \mathrm{CH}_{4}, \mathrm{CO}_{2}$ and $\left.\mathrm{CH}_{3} \mathrm{OH}\right) .{ }^{88-91}$ While we will focus the following discussion on $\mathrm{CO}$ due to the abundance of experimental evidence, we will highlight the main differences and the similarities when relevant. The key results of these experiments can be summarised as follows:

- The photo-desorption spectrum reflects the photo-absorption spectrum of solid CO, ${ }^{92}$ and hence the photo-desorption yield is modulated by the same wavelength dependence observed for the transition from the ground state of $\mathrm{CO}\left(X^{1} \Sigma^{+} ; v=0\right)$ to vibrational levels of the first allowed electronic state $\left(A^{1} \Pi\right)$. A strikingly similar conclusion was recently reported for the study of the photodesorption of NO ices. Also in this case, the desorption spectrum reflects the absorption spectrum of solid NO from Lu et al. (2008) in the 5 and $11.5 \mathrm{eV}$ range. ${ }^{93}$ This kind of photon-stimulated desorption (PSD) energy dependence was also observed for $\mathrm{CO}_{2}, \mathrm{CH}_{4}, \mathrm{O}_{2}$ and $\mathrm{N}_{2}{ }^{88-91,94}$ strengthening the idea that the electronic excitation responsible for desorption takes place in the condensed molecular film, and not in the substrate.

- CO PSD is driven by a three-step indirect Desorption Induced by Electronic Transition (DIET) process requiring: (i) electronic excitation of a sub-surface CO molecule by absorption of a UV photon; (ii) excitation of intermolecular vibrational modes following the rearrangement of neighbouring CO molecules around the excited molecule; and (iii) ejection of a surface CO molecule into the gas-phase. The data collected using layered binary ices made of ${ }^{12} \mathrm{CO}$ topped with ${ }^{13} \mathrm{CO}$ clearly show that the initial excitation step occurs within the 2 to 3 topmost molecular layers and hence, in order for this mechanism to occur, there have to be at least three monolayers of CO molecules. This conclusion also bears another important consequence, which is that the mechanism is independent of the thickness of the $\mathrm{CO}$ ice and of the substrate upon which the CO ice is grown. However, we need to stress here that other mechanisms might contribute to the overall desorption yield when the ice film is thin, e.g. a few monolayers, and hence when the excitation can reach the underlying substrate. This is the case for 
the substrate-induced dissociative electron attachment (DEA) desorption mechanism of ices grown on graphite as reported by Chakarov et al.. ${ }^{95,96}$ Complementary to this, the synchrotron studies on the DIET process show that, as long as the CO ice layer is thick enough, the three-step DIET process will take place with the same efficiency whether the substrate is a metal (polycrystalline gold), HOPG, solid water (SW) ice, both p-ASW and CSW.

The conclusion that CO photo-desorption involves only the upper layer and is triggered by vibronic excitation of a sub-surface $\mathrm{CO}$ molecule is supported by classical Molecular Dynamics (MD) simulations. ${ }^{97}$ These calculations, however, reveal that there are two CO photon-stimulated desorption mechanisms occurring upon irradiation of the $\mathrm{CO}$ ice: a direct process and an indirect one (the kick-out mechanism). The former involves only CO molecules at the vacuum interface, and competes with the indirect process making its observation difficult. In fact, the work of Hemert et al. ${ }^{97}$ shows that electronic excitation of the CO molecule promotes rotation and induces a rearrangement of the neighbouring molecules before relaxation to the ground state via internal conversion follows. This leaves the originally excited molecule in an unfavourable configuration with respect to the neighbouring species while also possessing a high degree of vibrational excitation. It is the unfavourable orientation and position that triggers desorption rather than the vibrational excitation. Hence, molecules in the next top layer contribute to desorption through a "kick-out" mechanism through which a neighbouring molecule in the covering layers desorbs while the originally excited molecule stays in the ice. This is akin to the "Newton's Cradle" mechanism proposed by King and Arnold from studies of ultrafast $\mathrm{C}_{6} \mathrm{H}_{6}$ desorption from $\mathrm{C}_{6} \mathrm{H}_{6}$ films. ${ }^{98}$ The simulations show that there is hardly any vibrational energy transferred after the internal conversion, so the photo-stimulated desorption is caused by a disruption of the local configuration around the excited $\mathrm{CO}$ molecule, or in other words "by the differences in anisotropy of ground and excited-state interaction potentials". ${ }^{97}$ This mechanism is consistent with the laboratory findings, although, by contrast, the original model proposed on the basis of the 
experiments only ${ }^{88}$ states that at least part of the energy of the excited sub-surface CO molecule is transferred to the upper species via the excitation of intermolecular vibrational modes. One might argue that in the case of the kick-out mechanism, the desorbing surface molecule would be vibrationally, rotationally and translationally cold, whereas in the other mechanism the escaping species would be vibrationally hot. Unfortunately, there is currently no experimental evidence to support these conclusions and further investigations are warranted.

One thing is certain, intermolecular interactions play an important role in determining the effective photon-stimulated desorption yield. Subsequent studies of more complex binary $\mathrm{CO}$ and $\mathrm{N}_{2}$ ices demonstrated that the measured photo-desorption rate is not modulated by the absorption spectrum of the desorbing molecule. Instead the wavelength dependence results from a combination of the absorption profiles of the surrounding species which are present deeper in the ice. Thus, the efficiency of the indirect DIET process driving photonstimulated desorption depends on the nature of the species, being very effective for $\mathrm{N}_{2}$ with $\mathrm{CO}$, less effective ${ }^{89}$ for $\mathrm{CH}_{4}$ with $\mathrm{CO}$ or $\mathrm{CO}_{2}$ with $\mathrm{CO},{ }^{90}$ and negligible ${ }^{91}$ for $\mathrm{CH}_{3} \mathrm{OH}$ with $\mathrm{CO}$ or for $\mathrm{H}_{2} \mathrm{O}$ and $\mathrm{CO} .{ }^{88}$ It should be noted that comparing the studies of $\mathrm{CH}_{4} / \mathrm{CO}$ and $\mathrm{N}_{2} / \mathrm{CO}$ reveals some evidence in support of a DIET mechanism that excludes a pure kick-out process. In fact, as Fillion and coworkers point out, $\mathrm{CH}_{4}$ is lighter than $\mathrm{N}_{2}$ so momentum transfer only originating from the excited sub-surface $\mathrm{CO}$ molecule would result in a more efficient desorption of the lighter $\mathrm{CH}_{4}$ contrary to experimental observations. ${ }^{89}$

It is clear now that:

- Photon-stimulated desorption is a wavelength-dependent process,

- and that care must be taken in using the measured photon-stimulated desorption rates for pure ices in complex astrochemical models because the molecule that is lifted off the surface is not necessarily the one that absorbs the photon. 
The latter concept was first reported in the work of Thrower et al. ${ }^{99,100}$ in near-UV irradiation of binary layered ices of $\mathrm{C}_{6} \mathrm{H}_{6}$ and $\mathrm{H}_{2} \mathrm{O}$. The study nicely illustrates how adsorbatemediated indirect photo-desorption of $\mathrm{H}_{2} \mathrm{O}$ can occur subsequent to resonant electronic excitation of the $\mathrm{C}_{6} \mathrm{H}_{6}$ adsorbate on the $\mathrm{H}_{2} \mathrm{O}$ ice through unimolecular decay on the ground electronic state surface of a cluster in which $\mathrm{C}_{6} \mathrm{H}_{6}$ is $\pi$ H-bonded to a number of $\mathrm{H}_{2} \mathrm{O}$ molecules in the surface. To the best of our knowledge, this experimental investigation was one of a very few ${ }^{101,102}$ to measure the kinetic energy of the desorbing molecules upon photon irradiation of ices of astrophysical interest. There remain exciting challenges ahead of us in studying, both experimentally and theoretically, the partitioning of energy into translational, rotational and vibrational degrees of freedom of the photodesorbed species, and how the excess energy can affect the low temperature chemistry in the gas phase of dark clouds.

Finally, the work of Thrower et al. ${ }^{99,100}$ also highlighted the potential importance of wavelengths longer than $200 \mathrm{~nm}$ when considering photo-processes in unsaturated, conjugated and aromatic molecules. Indeed, the wavelength dependence of astrophysically relevant radiation fields have an overall higher intensity between 200 - $600 \mathrm{~nm}$ than at shorter wavelengths (100 $-200 \mathrm{~nm}) .103$

\subsection{Radiolytic Interactions: Highly Efficient Electron-promoted De- sorption of Small Molecules from Solid Water}

Regardless of the growth mechanism of the icy shell coating interstellar grains, observations clearly confirm that $\mathrm{H}_{2} \mathrm{O}$ is the dominating chemical species in the solid phase ISM. ${ }^{104}$ Therefore, once the diffuse clouds evolve into dense molecular clouds, grains have accrued a thick water-rich mantle. From a physicochemical point of view, it is well known that the three dimensional network of molecules constituting solid $\mathrm{H}_{2} \mathrm{O}$ possesses a rather unique feature: a strong intermolecular interaction, namely hydrogen-bonding (H-bonding), that affects both macroscopic and microscopic properties in comparison to other simple molecular solids (e.g. 
$\left.\mathrm{CH}_{4}, \mathrm{CO}\right)$.

Recent experimental investigations have highlighted how H-bonding is intimately intertwined with the efficient capability of solid $\mathrm{H}_{2} \mathrm{O}$ in propagating non-thermal excitations through the ice itself, particularly from the bulk to the vacuum interface. ${ }^{28,29,105}$ The case study is the irradiation of layered binary ices of ASW topped with benzene $\left(\mathrm{C}_{6} \mathrm{H}_{6}\right)$ using electrons in the range of 100-350 eV. The results show an efficient non-thermal desorption mechanism (electron-promoted desorption, EPD), for $\mathrm{C}_{6} \mathrm{H}_{6}$ from solid $\mathrm{H}_{2} \mathrm{O}$. Regarding these experiments, one should recall that $\mathrm{C}_{6} \mathrm{H}_{6}-\mathrm{H}_{2} \mathrm{O}$ complexes have been shown to display two different types of hydrogen bonds. In fact, the aromatic molecule can act either as a hydrogen bond acceptor or as a hydrogen bond donor. In the former case, the $\pi$-electron density interacts with the $\mathrm{OH}$ group of $\mathrm{H}_{2} \mathrm{O}$, while in the latter case the $\mathrm{C}_{6} \mathrm{H}_{6}$ molecules bind with the lone pair of the O-atom, via a CH. . O interaction. ${ }^{28,105-115}$ Therefore, the $\mathrm{C}_{6} \mathrm{H}_{6} / \mathrm{H}_{2} \mathrm{O}$ system is a convenient model for the far more complex (in composition) water-dominated interstellar icy mantles. However, such simplification (of using binary ices) is necessary to probe the processes occurring solely at the $\mathrm{ASW} / \mathrm{C}_{6} \mathrm{H}_{6}$ interface and the transportation of excitations from the depths of the water bulk to the $\mathrm{C}_{6} \mathrm{H}_{6}$ (or vacuum) interface. In both cases, H-bonding plays a key role. It is important to stress that analogous experiments looking at $\mathrm{C}_{6} \mathrm{H}_{6}$ on a bare $\mathrm{aSiO}_{2}$ surface result in negligible EPD. This intimately links efficient EPD with $\mathrm{H}_{2} \mathrm{O}$ and the $\mathrm{H}$-bonding network in the solid $\mathrm{H}_{2} \mathrm{O}$. Further evidence of this important conclusion and its implications for the icy mantle growth of interstellar grains will be reported later on in this section.

Assuming first-order kinetics for the EPD process, a typical EPD trace ${ }^{28}$ is shown in Figure 5, where the experimental data (black full circles) is fitted by a bi-exponential function (solid blue line) that explicitly contains two desorption components: 


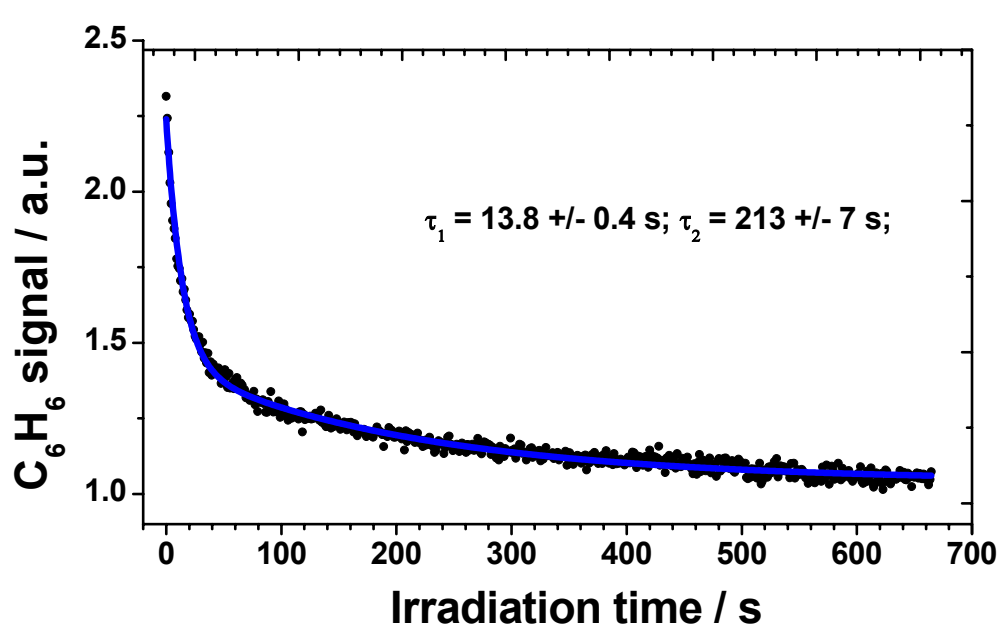

Figure 5: $\mathrm{C}_{6} \mathrm{H}_{6}$ EPD signal obtained for $5 \mathrm{~L}$ of $\mathrm{C}_{6} \mathrm{H}_{6}$ on $11 \mathrm{~nm}(100 \mathrm{~L})$ thick c-ASW. The experimental data are represented by black closed circles while the solid blue line is the result of fitting a two component decay model to the data as described in the text. Decay time constants are displayed in plot. Irradiation was conducted with $250 \mathrm{eV}$ electrons and initial beam current of $180 \mathrm{nA}$. Reproduced from reference 28 with permission of the PCCP Owner Societies.

$$
I(t)=I_{1} e^{-\sigma_{1} \phi_{1} t}+I_{2} e^{-\sigma_{2} \phi_{2} t}+I_{\infty}
$$

here $\sigma_{i}$ are the desorption cross-sections in $\mathrm{cm}^{2}$ for the fast $(i=1)$ and slow $(i=2)$ component, $I_{i}$ is the corresponding amplitude, and $I_{\infty}$ is the residual.

In order to understand the physical meaning of the two components, a series of electron irradiation experiments was performed for $\mathrm{ASW} / \mathrm{C}_{6} \mathrm{H}_{6}$ ices as summarised in Figure 6 . In all cases, first a compact film of amorphous $\mathrm{H}_{2} \mathrm{O}$ was deposited on top of a silica substrate at $c a$. $110 \mathrm{~K}$ which was then capped with $\mathrm{C}_{6} \mathrm{H}_{6}$. The binary system was subsequently bombarded with electrons while the QMS was employed to detect desorbing aromatic molecules during the irradiation. In panel A, the thickness of the ASW under-layer is kept constant to a thick film regime while $\mathrm{C}_{6} \mathrm{H}_{6}$ exposure is progressively increased $(0.5 \mathrm{~L}, 5 \mathrm{~L}, 50 \mathrm{~L}, 200 \mathrm{~L})$ from a sub-monolayer to the multilayer regime. ${ }^{28}$ The observed desorption trace is shown to change significantly depending on the overlayer thickness as clearly displayed by Figure 7 . 

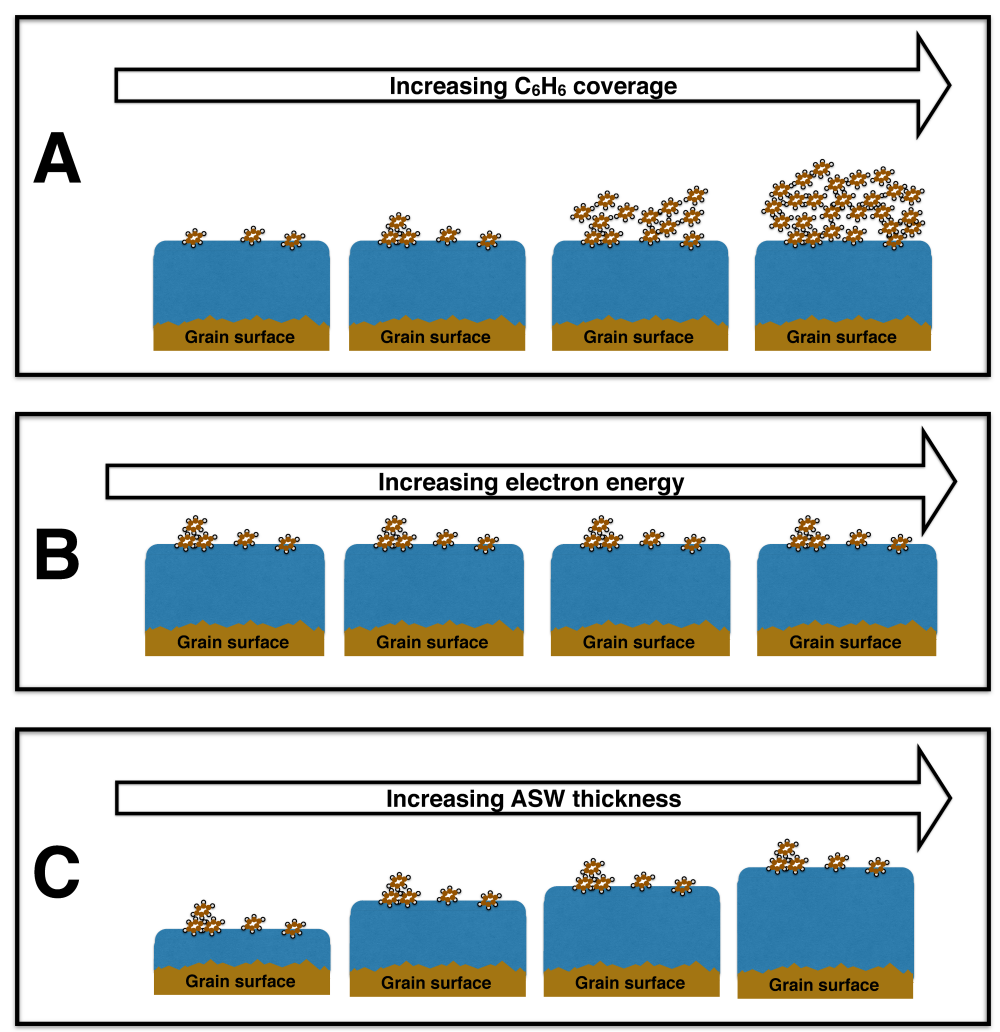

Figure 6: Cartoon summarising the EPD experiments for $\mathrm{ASW} / \mathrm{C}_{6} \mathrm{H}_{6}$ ices by changing: the $\mathrm{C}_{6} \mathrm{H}_{6}$ coverage (panel A); electron energy (panel B) and the thickness of the $\mathrm{H}_{2} \mathrm{O}$ underlayer (panel C). 


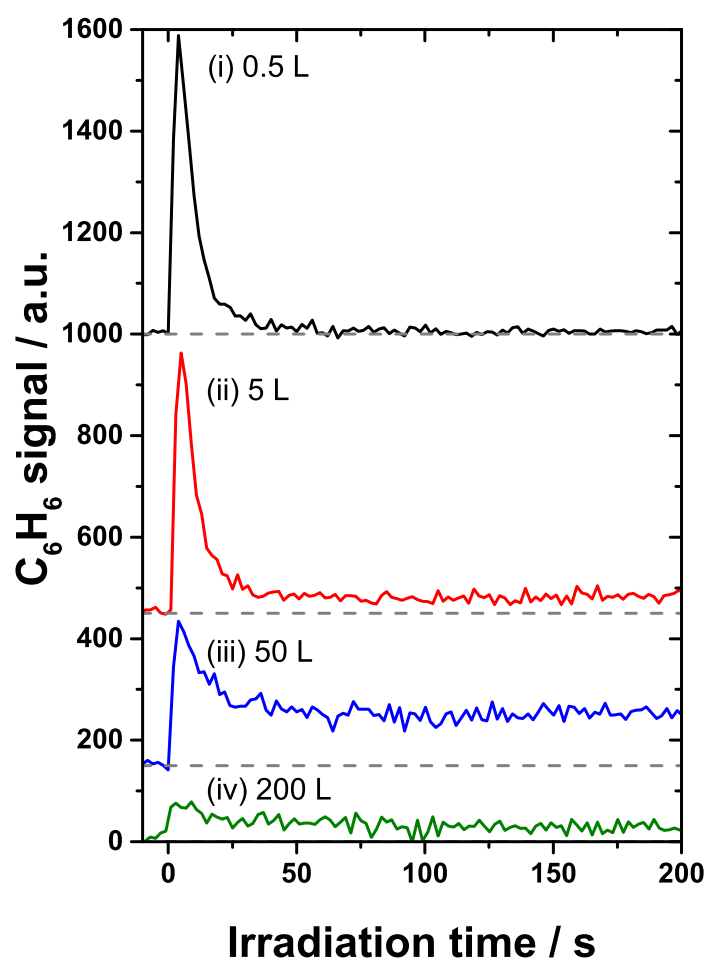

Figure 7: $\mathrm{C}_{6} \mathrm{H}_{6}$ EPD traces for (i) 0.5, (ii) 5, (iii) 50 and (iv) $200 \mathrm{~L}$ of $\mathrm{C}_{6} \mathrm{H}_{6}$ adsorbed on a thick c-ASW film. The ices were irradiated with $300 \mathrm{eV}$ electrons with a beam current of $100 \mathrm{nA}$. Traces are offset for clarity with the dashed lines showing the zero lines for each. The desorption signal for $200 \mathrm{~L}$ is significantly reduced compared to the low coverage experiments. Reproduced from reference 28 with permission of the PCCP Owner Societies 
As a relatively thick film of $\mathrm{C}_{6} \mathrm{H}_{6}$ (e.g. $200 \mathrm{~L}$ ) accrues on top of the ASW ice, the desorption trace decreases significantly in intensity and the observed profile matches that observed with for bulk $\mathrm{C}_{6} \mathrm{H}_{6}$ on bare $\mathrm{aSiO}_{2} .{ }^{28,105}$ This supports the hypothesis of the key role played by the c-ASW film in driving desorption of the aromatic molecules. In other words, the $\mathrm{H}_{2} \mathrm{O}$ ice is a necessary substrate to observe the efficient desorption of the $\mathrm{C}_{6} \mathrm{H}_{6}$ molecules. Below the thick benzene film regime (e.g. $50 \mathrm{~L})$, the typical observed desorption trace displays two components, each with particularly large cross-sections. A fast component $\left(\sigma_{1}\right)$, with a cross-section up to $10^{-15} \mathrm{~cm}^{2}$ can be attributed to desorption of isolated $\mathrm{C}_{6} \mathrm{H}_{6}$ molecules that are hydrogen-bonded to small clusters of water molecules on the ASW surface. This process is more evident in the low coverage experiments (e.g. $0.5 \mathrm{~L})$. A slower component $\left(\sigma_{2}\right)$, with a cross-section of ca. $10^{-17} \mathrm{~cm}^{2}$, is attributed mainly to $\mathrm{C}_{6} \mathrm{H}_{6}$ desorption from larger $\mathrm{C}_{6} \mathrm{H}_{6}$ islands on the solid water surface, which is more relevant at intermediate coverage $(\geq 5 \mathrm{~L})$.

At intermediate exposures, where $\mathrm{C}_{6} \mathrm{H}_{6}$ forms islands, some molecules will still be $\mathrm{H}-$ bonded to the icy substrate leading to observations of both the fast and the slow desorption components. It follows that the latter does not only contain the contribution to the signal from $\mathrm{C}_{6} \mathrm{H}_{6}$ desorbing from multilayer $\mathrm{C}_{6} \mathrm{H}_{6}$, but might be enhanced as a result of the islands disrupting, morphological changes within the ice. It is possible that non-thermal diffusion of islanded $\mathrm{C}_{6} \mathrm{H}_{6}$ towards the dangling $\mathrm{OH}$ at the interface can also intensify the desorption yield during the irradiation.

Panel B in Figure 6 represents another set of experiments investigating the energy dependence of the EPD decay profiles, and hence how the desorption cross-sections varies with the energy of the primary electrons $(100 \mathrm{eV}, 150 \mathrm{eV}, 200 \mathrm{eV}, 250 \mathrm{eV}, 300 \mathrm{eV}, 350 \mathrm{eV})$. The study concludes that the cross-sections of the two components remain relatively constant in that energy range. ${ }^{105}$ However, irradiation of a $10 \mathrm{~L} \mathrm{C}_{6} \mathrm{H}_{6}$ film on c-ASW at higher energies $(250 \mathrm{eV}, 300 \mathrm{eV}, 350 \mathrm{eV})$ results in the growth component in the desorption profile at around 
50-70 s and delaying of the slow component (see reference 105). A subsequent study ${ }^{28}$ has linked this effect to morphological changes within the $\mathrm{H}_{2} \mathrm{O}$ ice at these higher electron energies. When the electron energy is at its highest, amorphisation of the $\mathrm{H}_{2} \mathrm{O} /$ vacuum interface is accompanied by disruption of the $\mathrm{C}_{6} \mathrm{H}_{6}$ islands producing more $\mathrm{C}_{6} \mathrm{H}_{6} \mathrm{H}$-bonded to the c-ASW surface which contributes to the rising signal in the profile and delays the slow desorption component.

Finally, in panel $\mathrm{C}$ (Figure 6), the $\mathrm{C}_{6} \mathrm{H}_{6}$ exposure is kept constant at $5 \mathrm{~L}$ while the thickness of the underlying c-ASW ice is varied. In this situation, the observed desorption profile at $250 \mathrm{eV}$ remains unchanged in the range of the $\mathrm{H}_{2} \mathrm{O}$ doses explored $(70 \mathrm{~L}, 100 \mathrm{~L}, 200 \mathrm{~L}$, $500 \mathrm{~L}$ ). This confirms that the observed phenomena are not associated with the substrate on which the c-ASW is deposited on. ${ }^{28}$

The mechanism that has been proposed is based on previous electron irradiation experiments of $\mathrm{H}_{2} \mathrm{O}$ ices and on optical-absorption and electron-energy-loss spectroscopy (EELS) of solid and liquid water. ${ }^{116-123}$ The primary electrons, employed in the above discussed experiments, possess sufficient kinetic energy that the incident beam is transmitted, almost unaffected, through the entire $\mathrm{C}_{6} \mathrm{H}_{6}$ film for low and intermediate exposures (up to $50 \mathrm{~L}$ ) reaching the bulk of the $\mathrm{H}_{2} \mathrm{O}$ ice. Here a cascade of electronic excitations, ionisation events and secondary electrons results from inelastic scattering of the primary (and secondary) electrons with the water molecules. These cascade processes are compatible with electronic excitations of the O-atom lying at $8.7 \mathrm{eV}, 10.4 \mathrm{eV}$ and at $14.5 \mathrm{eV}^{116,121,123}$ and result in the formation of long-lived excitons in the bulk of the c-ASW film. Most importantly, the extended three-dimensionality of the H-bonding network within c-ASW provides a transportation route for the excitons over large distances (potentially tens of $\mathrm{nm}$ ) from the bulk to interfaces. Whereas the relatively weak H-bonding between $\mathrm{C}_{6} \mathrm{H}_{6}$ and ASW allows the excitation to be transferred to the aromatic ring via dangling $\mathrm{OH}$ groups and/or exciton 
relaxation and excitation of the hydrogen bond followed by desorption.

In conclusion, the observed EPD seems to be peculiar for adsorbates interacting with the $\mathrm{H}_{2} \mathrm{O}$ surface via $\mathrm{H}$-bonding. Further evidence supporting this hypothesis was obtained in a follow-up EPD experiments employing methanol $\left(\mathrm{CH}_{3} \mathrm{OH}\right)$ and diethyl ether $\left(\mathrm{CH}_{3} \mathrm{CH}_{2} \mathrm{OCH}_{2} \mathrm{CH}_{3}\right)$ ices rather than c-ASW as substrates. ${ }^{28,29}$ The decreased extent of the H-bonding network (or its absence as for $\mathrm{CH}_{3} \mathrm{CH}_{2} \mathrm{OCH}_{2} \mathrm{CH}_{3} / \mathrm{C}_{6} \mathrm{H}_{6}$ ices) limits the propagation of excitons from the bulk to the substrate $/ \mathrm{C}_{6} \mathrm{H}_{6}$ interface. Therefore, only the outer $\mathrm{CH}_{3} \mathrm{OH}$ layers could potentially promote the $\mathrm{C}_{6} \mathrm{H}_{6}$ desorption efficiently. Thus, it comes as no surprise that these experiments show that $\mathrm{C}_{6} \mathrm{H}_{6} \mathrm{EPD}$ from $\mathrm{CH}_{3} \mathrm{OH}$ or $\mathrm{CH}_{3} \mathrm{CH}_{2} \mathrm{OCH}_{2} \mathrm{CH}_{3}$ is a minor process with respect to the analogous system of $\mathrm{ASW} / \mathrm{C}_{6} \mathrm{H}_{6}$ (Figure 8). Data originally published in reference 29 have been re-plotted and shown in Figure 8.
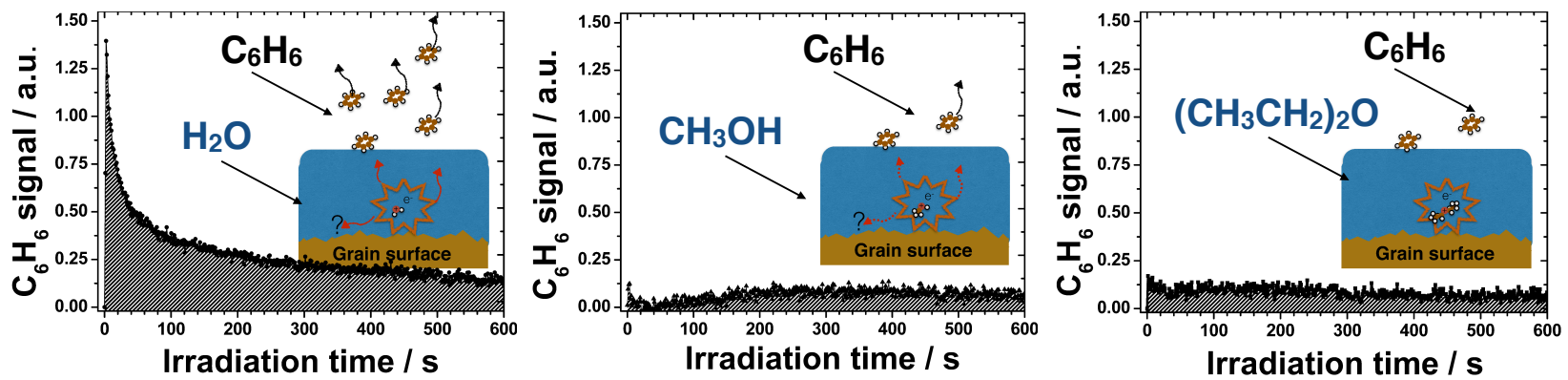

Figure 8: Comparison of the $\mathrm{C}_{6} \mathrm{H}_{6}$ EPD traces from solid $\mathrm{H}_{2} \mathrm{O}$ (left panel), $\mathrm{CH}_{3} \mathrm{OH}$ (central panel), and $\mathrm{CH}_{3} \mathrm{CH}_{2} \mathrm{OCH}_{2} \mathrm{CH}_{3}$ (right panel). The signal is significantly decreased, although still observed, when the substrate underlying the $5 \mathrm{~L}$ of $\mathrm{C}_{6} \mathrm{H}_{6}$ is made of C-containing molecules. These results support the idea that a three dimensional H-bonding network propagates the O-centred excitations within the ice, while introducing methyl $\left(\mathrm{CH}_{3}\right)$ and ethyl $\left(\mathrm{CH}_{2} \mathrm{CH}_{3}\right)$ groups bring additional electron-rich centres capable of being excited by the primary and secondary electrons which channel this excitation to favour other processes over exciton migration and desorption. Cartoons visually show the efficiency of the proposed mechanism for the three ices. Data have been re-plotted from reference 29 with permission of the PCCP Owner Societies.

The cartoons in each plot highlight how, even assuming exciton formation in the $\mathrm{CH}_{3} \mathrm{OH}$ and $\mathrm{CH}_{3} \mathrm{CH}_{2} \mathrm{OCH}_{2} \mathrm{CH}_{3}$ ices, the decreased extent of the hydrogen-bonding network limits 
the propagation of the excitation energy to the $\mathrm{C}_{6} \mathrm{H}_{6}$ over-layer promoting $\mathrm{C}_{6} \mathrm{H}_{6}$ desorption. Different mechanisms can be attributed to the observed signal for $\mathrm{CH}_{3} \mathrm{OH} / \mathrm{C}_{6} \mathrm{H}_{6}$ and $\mathrm{CH}_{3} \mathrm{CH}_{2} \mathrm{OCH}_{2} \mathrm{CH}_{3} / \mathrm{C}_{6} \mathrm{H}_{6}$ systems. A more detailed discussion can be found in the provided references. ${ }^{28,29}$

On the basis of these data, the relevance of efficient EPD from ASW surfaces in the ISM can now be discussed. Clearly, as the icy mantles on ISM dust grains consist primarily of $\mathrm{H}_{2} \mathrm{O}$, non-thermal desorption of small molecules bound to the ice surface via a dangling $\mathrm{OH}$ group is entirely feasible given the presence of cosmic rays and other ionising radiations in relevant regions. However, two issues have to be addressed: (i) how the above reported laboratory results are appropriate for consideration in an astrophysical context, and (ii) what species could more likely be involved in such context.

Electron irradiation experiments can simulate the secondary electron flux forming subsequent to ionising radiation with interstellar ices. This statement is reasonable when one considers the differential cosmic ray flux for protons in the energy range $1-10^{6} \mathrm{MeV}_{\text {nucleon }}{ }^{-1}$ in the interstellar medium, ${ }^{124}$ which displays a relatively flat distribution between $1-100 \mathrm{MeV}$ with a maximum around 40-50 MeV. In this energy range, the ions will deposit most of their energy in the ice through electron scattering events. ${ }^{28}$ These interactions produce an ionisation track within the mantle which is rich in secondary electrons having energy distributions in the low energy tail overlapping with the electronic excitation of condensed $\mathrm{H}_{2} \mathrm{O} .{ }^{125,126}$ In a similar fashion (inelastic scattering followed by ionisation), an analogous flux of secondary electrons to that associated with cosmic rays can form subsequent to irradiation with the primary electron beam used in the experiments as reported above. The recent work by Herbst and co-workers reinforces the importance of this type of radiation-induced physics and chemistry. ${ }^{127}$ 
The aforementioned EPD experiments were conducted using $\mathrm{C}_{6} \mathrm{H}_{6}$ which is not known to be particularly abundant in the ice of the ISM. However, it has been observed in the gas-phase through its $\nu_{4}$ bending mode at $674 \mathrm{~cm}^{-1} .{ }^{128}$ Moreover, the recent detection of benzonitrile $\left(\mathrm{C}_{6} \mathrm{H}_{5} \mathrm{CN}\right)^{129}$ in the ISM strengthens the idea that, although elusive, $\mathrm{C}_{6} \mathrm{H}_{6}$-like molecules and polycyclic aromatic hydrocarbons (PAHs), are indeed present. It should be noted that, when the abundance of benzonitrile is computed in the cold-core Taurus Molecular Cloud 1 (TMC-1), the column density is smaller than that detected by nearly a factor of 4 . However, the same model predicts abundances of cyanopolyynes that match the observations within a factor of 2. The authors explain this mismatch by stating that their model does not take into account cosmic-ray driven chemistry in icy grains, although for "such grain-surface processes to contribute to gas-phase abundances, there must exist efficient non-thermal desorption mechanisms". ${ }^{129}$ In regards of this conclusion, the electron irradiation experiments of $\mathrm{C}_{6} \mathrm{H}_{6}$ could well support the idea that $\mathrm{C}_{6} \mathrm{H}_{5} \mathrm{CN}$ can also undergo the same processes with a similar high cross-section as for $\mathrm{C}_{6} \mathrm{H}_{6}$. Thus, the EPD experiments could provide the missing route to liberate solid-phase synthesised species (e.g. $\mathrm{C}_{6} \mathrm{H}_{5} \mathrm{CN}$ ) into the gas-phase provided they are weakly bound to the ASW surface via H-bond interactions.

A previous study on electron irradiation of $\mathrm{CH}_{3} \mathrm{CN}$ on c-ASW using IR spectroscopy resulted in an EPD cross-section with a consistent value $\left(10^{-17} \mathrm{~cm}^{2}\right)$ to that reported for the slow (second) component observed for $\mathrm{C}_{6} \mathrm{H}_{6}$ on c-ASW $\left(\sigma_{2}\right)$. Unfortunately, the RAIRS experiment cannot probe fast processes, and hence measure the cross-section corresponding to the fast-decay in the EPD profile $\left(\sigma_{1}\right)$. However, it still provides an important window on the long timescale processes where penetration of the electrons deep into the bulk solid, exciton transport and reaction product diffusion are important. ${ }^{130}$ This result corroborates the intriguing idea that the exciton-driven mechanism, observed in the electron irradiation of ASW, can lead to non-thermal desorption of any small molecule sitting on top of the icy shell as long as there is a relatively weak intermolecular interaction (H-bonding) between ad- 
sorbate and ASW substrate. It follows that this might be the case of an abundant molecule like CO. The current view of the interstellar icy mantles pictures a CO layer on top of the ASW inner layers. Therefore, $\mathrm{CO}$ bound to $\mathrm{H}_{2} \mathrm{O}$ could be ejected into the gas-phase by an efficient EPD process. Clearly, an additional efficient desorption step might potentially delay the mantle enrichment in $\mathrm{CO}$, and hence its hydrogenation products including the formation of methanol $\left(\mathrm{CH}_{3} \mathrm{OH}\right)$ and in turn, of other organic molecules.

As published elsewhere, ${ }^{28}$ it was possible to tentatively estimate the rate constants for both EPD and PSD processes of isolated CO molecules (sub-monolayer and monolayer) Hbound to ASW in cold, dense objects. The resulting ratio between the two rate constants, $k_{E P D} / k_{P S D}$, suggests that the fast EPD process would be about one order of magnitude more efficient than PSD in returning CO to the gas phase in such environments.

A consequence of this is that in a cooling environment $\mathrm{CO}$ deposition is slowed on the water surface compared to the more weakly binding $\mathrm{aSiO}_{2}$ surface as the latter does not exhibit the highly efficient EPD seen on an ASW surface. This is illustrated by the toy model calculations reported in the Section 4 of this article.

The presence of an additional efficient desorption channel influencing the gas-grain interchange cannot be ignored and should be taken into account for more realistic astrochemical models. However, this would benefit from further laboratory data. To date, the vast majority of electron/ion irradiation experiments on interstellar ice analogues focus on the chemistry induced upon exposure to ionizing bombardment; ${ }^{131-136}$ fewer look at the desorbing species. ${ }^{137-140}$ It is even rarer to see both processes compared, as in the work of Abdulgalil et al. ${ }^{141}$ This study reports that ion/electron induced chemistry is dominant in those environments where the ices are relatively thick (hundreds of layers thick), while EPD is significant when ices are thinner, which is the case as diffuse clouds transition to being dense clouds 
when reactive accretion has not yet reached a steady state.

\subsection{Radiolytic Interactions: Efficient Hydrogen Production from Hydrogenated Carbon-containing Molecules}

The efficiency of the $\mathrm{C}_{6} \mathrm{H}_{6} \mathrm{EPD}$ from $\mathrm{ASW}$, with respect to $\mathrm{C}_{6} \mathrm{H}_{6}$ EPD from $\mathrm{CH}_{3} \mathrm{OH}$ and from $\mathrm{CH}_{3} \mathrm{CH}_{2} \mathrm{OCH}_{2} \mathrm{CH}_{3}$ surfaces with progressively decreasing degree of $\mathrm{H}$-bonding in the substrate film, was discussed above. This work prompted a further question. What other processes are favoured over $\mathrm{C}_{6} \mathrm{H}_{6}$ desorption for organic substrates? Electron irradiation experiments on binary, layered ices comprising $\mathrm{C}_{6} \mathrm{H}_{6}$ on the three substrates were repeated while desorption of other species was monitored. The results, although preliminary, clearly show that electron-induced chemistry (EIC) leads to the formation of $\mathrm{H}_{2}$ competitively with (in the case of $\mathrm{H}_{2} \mathrm{O}$ ) or dominating over (in the case of the organic substrates) $\mathrm{C}_{6} \mathrm{H}_{6}$ desorption. ${ }^{142}$ Indeed, $\mathrm{H}_{2}$ formation and desorption are common processes to the three systems but are clearly more significant for organic-based ices than in ASW. Briefly, this remarkable difference can be addressed by considering the presence of electronic excitations localized around the $\mathrm{C}$ atom versus those involving the $\mathrm{O}$ atom, with the former favouring reactive routes. These results, along with work from other groups, ${ }^{104,143,144}$ highlight two open challenges in astrochemistry:

1. the need to fully understand the distribution of products (branching ratios) of photonand charged-particle-induced physics and chemistry; and

2. the importance of looking at the nature of the species leaving the surface and not simply at what remains on and in the ice if we are to incorporate these processes into astrochemical models.

Consistency with what is known of the radiolysis of liquids and vapours ${ }^{145,146}$ would suggest that $\mathrm{H} / \mathrm{H}_{2}$ production is likely to be an important process in photolysis and radiolysis of both simple (e.g. water-rich) and complex (e.g. containing complex organic molecules; 
COMs) ices, ${ }^{133,147-149}$ which leads to the question as to what extent does the formation and desorption of $\mathrm{H} / \mathrm{H}_{2}$ can contribute to hydrogen recycling in the ISM? At the early stages of dense cloud formation, gaseous $\mathrm{H}$ is depleted onto grains to form $\mathrm{H}_{2} \mathrm{O}, \mathrm{NH}_{3}$, and $\mathrm{CH}_{4}$ by reacting with $\mathrm{O}, \mathrm{C}$ and $\mathrm{N}$ atoms. Later, irradiation of these simple molecules as icy mantles accrue would promote EIC. On one hand, this yields radicals and enriches the ice in COMs but, on the other, seems to return $\mathrm{H}_{2}$ to the gas phase, leaving residues that will potentially become increasingly unsaturated and with time probably aromatic. If this conclusion was to be confirmed, the formation and enrichment of the solid phase of conjugated systems will push the absorbance spectrum into the visible region, opening up, in turn, new channels for non-thermal desorption and photochemistry of other species interacting with the aromatic ring. Further experiments are required to reinforce these intriguing speculations.

\section{Astrophysical Implications}

Depending on the temperature and the nature of species involved, the mobility and diffusion of these species in the solid state may be possible on interstellar dust grains, as discussed. It is important to realise the consequences of the presence of binding energy distributions driving the gas adsorption on the ice. Differences in desorption energy reflect differences in adsorption sites. If a molecule is known to diffuse and to desorb from multilayers, then such molecules will behave differently to molecules known to desorb from the monolayer. Binding energies can therefore have a direct impact on how icy films are grown on a dust grain. The desorption behaviour of $\mathrm{CO}$ on dust grain surfaces and $\mathrm{H}_{2} \mathrm{O}$ has been mentioned in the previous section and from the information therein reviewed Figure 9 can be made.

With $\mathrm{H}_{2} \mathrm{O}$ present in clustered environments in the form of islands, bare dust grain surfaces will be available. As the surface temperature decreases while the dust grain travels toward denser regions of dust clouds, gas-phase CO (black curve) will begin to adsorb. The 

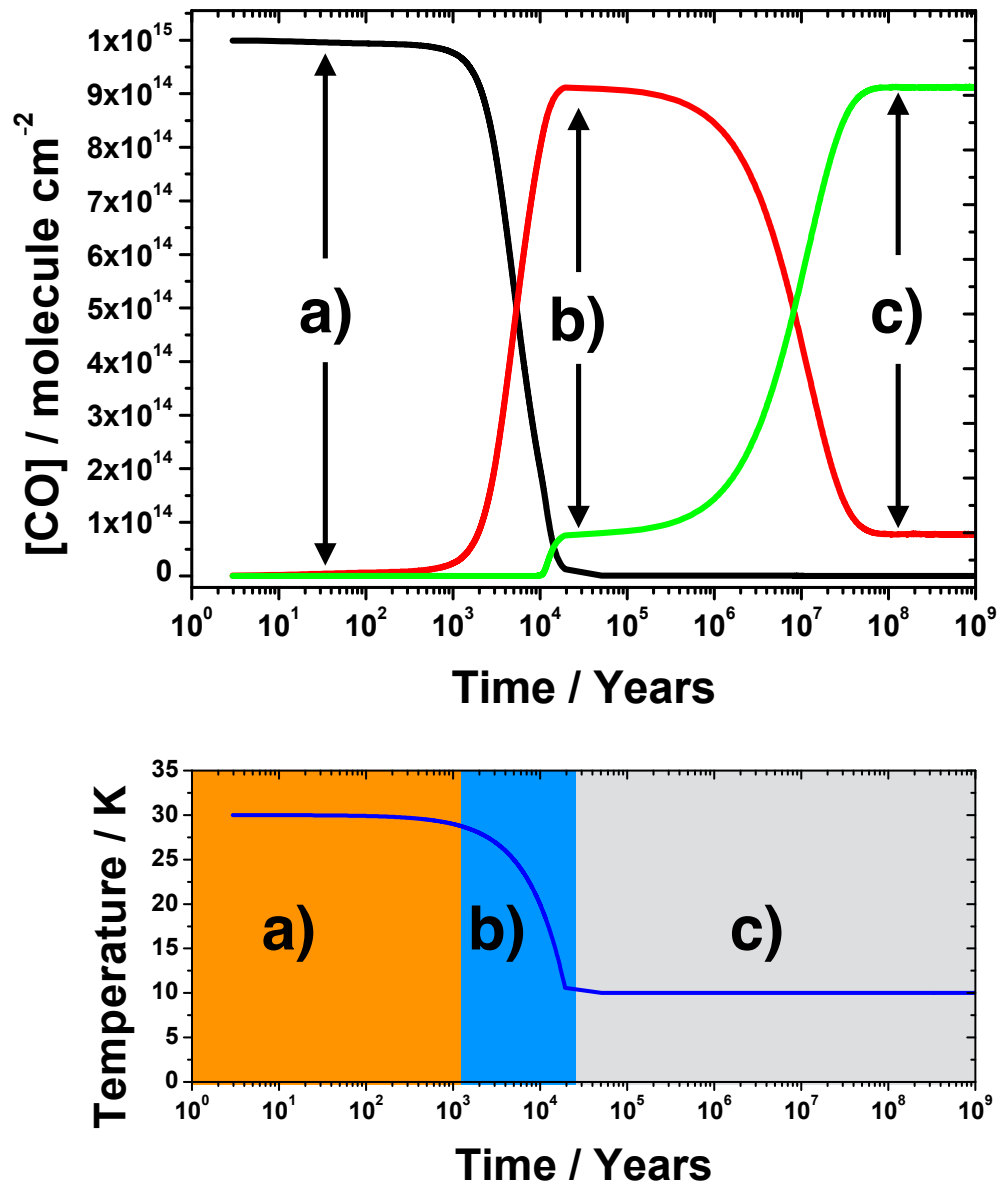

Figure 9: The upper panel shows the number of CO molecules per unit of area (molecules $\mathrm{cm}^{-2}$ ) in the gas phase (black line), adsorbed on water ice (red line), and adsorbed on $\mathrm{aSiO}_{2}$ (green line) as a function of time (years). As the time increases, the temperature decreases. This is shown in the lower panel (blue curve). The labels $\mathrm{a}, \mathrm{b}$ and $\mathrm{c}$ highlight three main stages of the simulation: an initial situation when the temperature is $c a .30 \mathrm{~K}$ and $\mathrm{CO}$ is mainly found in the gas-phase (a), the subsequent CO-freeze out due to the cooling down to ca. $10 \mathrm{~K}(\mathrm{~b})$, and rearrangement and evolution of the system in isothermal conditions due to non-thermal desorption (c). 
resulting kinetic model can be presented as below:

$$
\begin{array}{r}
\mathrm{CO}(\mathrm{g}) \rightarrow \mathrm{CO}_{\mathrm{SiO}_{2}}(\mathrm{~s}) \\
\mathrm{CO}(\mathrm{g}) \rightarrow \mathrm{CO}_{\mathrm{H}_{2} \mathrm{O}}(\mathrm{s}) \\
\mathrm{CO}_{\mathrm{H}_{2} \mathrm{O}}(\mathrm{s}) \stackrel{\text { heat }}{\longrightarrow} \mathrm{CO}(\mathrm{g}) \\
\mathrm{CO}_{\mathrm{SiO}_{2}}(\mathrm{~s}) \stackrel{\text { heat }}{\longrightarrow} \mathrm{CO}(\mathrm{g}) \\
\mathrm{CO}_{\mathrm{H}_{2} \mathrm{O}}(\mathrm{s}) \stackrel{h \nu}{\longrightarrow} \mathrm{CO}(\mathrm{g}) \\
\mathrm{CO}_{\mathrm{SiO}_{2}}(\mathrm{~s}) \stackrel{h \nu}{\longrightarrow} \mathrm{CO}(\mathrm{g}) \\
\mathrm{CO}_{\mathrm{H}_{2} \mathrm{O}}(\mathrm{s}) \stackrel{e^{-}}{\longrightarrow} \mathrm{CO}(\mathrm{g})
\end{array}
$$

In this toy model, we take into account:

1. the parallel adsorption kinetics of $\mathrm{CO}$ on both $\mathrm{ASW}$ and $\mathrm{aSiO}_{2}$ (Eq. 7a; Eq. 7b) the rate of which is simply determined by the gas temperature in $Z_{W}$ (as defined in Eq. 1), with both species having a sticking coefficient of 1 (though the accommodation coefficient is determined by the balance of adsorption and desorption);

2. CO thermal desorption from both $\mathrm{ASW}$ and $\mathrm{aSiO}_{2}$ surfaces using the most probable binding energies of $12 \mathrm{~kJ} \mathrm{~mol}^{-1}$ and $8 \mathrm{~kJ} \mathrm{~mol}^{-1}$ respectively ${ }^{37}$ (Eq. 7c; Eq. 7d) assuming $10^{12} \mathrm{~s}^{-1}$ for the pre-exponential factor. No account is taken for the distribution of the adsorption energies and there is no diffusion of either $\mathrm{CO}$ and $\mathrm{H}_{2} \mathrm{O}$ built into this toy model. However, earlier in the text, an independent model for $\mathrm{H}_{2} \mathrm{O}$ diffusion suggested agglomeration on a timescale of a few 1000s of years (Figure 4) leaving areas of $\mathrm{aSiO}_{2}$ bare and directly accessible by other species such as CO. Therefore, this conclusion justifies the choice of considering adsorption-desorption mechanisms for CO and $\mathrm{aSiO}_{2}$ in our simple model.

3. Furthermore, the simulation accounts for non-thermal desorption driven by VUV pho- 
tons (Eq. 7e; Eq. 7f) and by secondary electron excitations (Eq. 7g) produced by cosmic ray interactions. The former was assumed to be temperature and substrate independent with a rate of $4.2 \times 10^{-16} \mathrm{~s}^{-1}$. This value was obtained by multiplying the yield of the process ${ }^{87}\left(1.8 \times 10^{-2}\right)$ by photon absorption cross-section for $\mathrm{CO}$ in the VUV range ${ }^{150}$ between $120 \mathrm{~nm}$ and $160 \mathrm{~nm}\left(4.7 \times 10^{-18} \mathrm{~cm}^{2}\right)$, and by the estimated VUV flux in dense clouds, which is dominated by the emission from $\mathrm{H}_{2}$ excited by cosmic rays, that is typically about $5 \times 10^{3}$ photon $\mathrm{cm}^{-2} \mathrm{~s}^{-1} \cdot{ }^{124,151}$ The EPD CO rate was set to be $4.5 \times 10^{-15} \mathrm{~s}^{-1}$ as discussed in our previous work on $\mathrm{C}_{6} \mathrm{H}_{6} / \mathrm{ASW},{ }^{28}$ and being active through a mechanism that takes place only for solid $\mathrm{H}_{2} \mathrm{O}$ substrates and not for $\mathrm{aSiO}_{2}$ surfaces in order to reflect that there is no evidence of exciton transport in the latter system. This may be an extreme assumption, which has been proven for $\mathrm{C}_{6} \mathrm{H}_{6}{ }^{28,105}$ but needs to be tested experimentally for $\mathrm{CO}$.

As can be seen from this simple model, at first the temperature is too high for $\mathrm{CO}$ to efficiently adsorb on the icy grain (black curve, label a in Figure 9 and Figure 10), then, as the temperature drops below $30 \mathrm{~K}, \mathrm{CO}$ will adsorb on both solid water (red curve, label $\mathbf{b}$ in Figure 9) and bare silica (green curve, label b in Figure 9).
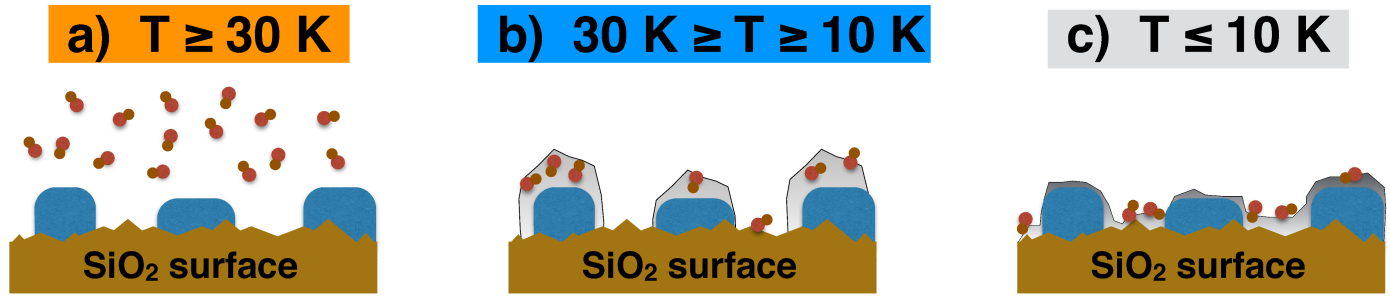

Figure 10: Cartoons showing three limiting situations summarising the laboratory findings as discussed in the text. In panel a the grain surface temperature is too high for $\mathrm{CO}$ to condensate, but cold enough to have islands of water ice forming on top of the silica substrate that represents the grain. The cartoon in the middle (panel b) shows the CO freeze-out on top of ASW preferably than on top of $\mathrm{aSiO}_{2}$ surfaces as the temperatures drops. Once the system is at $10 \mathrm{~K}$ the non-thermal desorption mechanisms drive the relocation of $\mathrm{CO}$ from the top of the ASW islands to the silica surface leading to the situation where $\mathrm{aSiO}_{2}$ is predominantly covered by $\mathrm{CO}$ with respect to ASW, as shown in panel c. 
From TPD data ${ }^{15,37,41,152}$ we know $\mathrm{CO}$ forms a full monolayer on solid $\mathrm{H}_{2} \mathrm{O}$ and $\mathrm{SiO}_{2}$ before a multilayer growth commences because binding sites for $\mathrm{CO}-\mathrm{H}_{2} \mathrm{O}$ are preferred over $\mathrm{CO}-\mathrm{CO}$ and over $\mathrm{CO}$ with $\mathrm{aSiO}_{2}$. Thus, $\mathrm{CO}$ will begin to grow on $\mathrm{H}_{2} \mathrm{O}$ islands in these simple models while only $10 \%$ of CO adsorbs onto the bare silica surface (label $\mathbf{b}$ in Figure 9 and Figure 10). Interestingly, EPD and PSD of CO seem to have no notable effect at earlier times (and at higher temperatures than $10 \mathrm{~K}$ ) in this simple model. This was tested by a control simulation with EPD and PSD channels switched off. However, non-thermal desorption becomes significant at later times, during the isothermal stage at $10 \mathrm{~K}$ of our simulation, (indicated by label $\mathbf{c}$ in Figure 9) by favouring the depletion of CO from solid $\mathrm{H}_{2} \mathrm{O}$ with respect to $\mathrm{aSiO}_{2}$ surfaces, which are in turn covered by icy $\mathrm{CO}$ (label c in Figure 10). It is important to stress that the aim of presenting this simple toy model is not to replace far more elaborate existing models, but to highlight how experimental findings can challenge and further our understanding of the interstellar icy grain structure while exploring the physics of these systems and homing in on the future key laboratory experiments. For instance, a catalogue of how molecules interact with $\mathrm{H}_{2} \mathrm{O}$ islands compared to dust grain surfaces, combined with their diffusion properties would provide a fuller picture of how icy mantles grow. Such a catalogue could also be used to determine the surface temperature of dust grains with sub-monolayer quantities of catalogued species. Determining if, e.g., CO is present solely on the $\mathrm{H}_{2} \mathrm{O}$ surface would mean the dust grain temperature is hotter than if $\mathrm{CO}$ is found on bare dust grain surface.

\section{Conclusions}

The key results reported in this work can be summarized in the following bulleted list below.

1. De-wetting, agglomeration and segregation of molecules on the cold surfaces of interstellar grains are important processes shaping the structure of the icy mantles. For simple systems, experimental evidence and literature reports of $\mathrm{H}_{2} \mathrm{O}$ de-wetting the 

range of potential grain surfaces that we might find in the interstellar medium? We would argue that the consistency of the agglomeration behaviour observed on silica and graphite in our work would suggest that similar behaviour would be expected for all substrates that show evidence of de-wetting of $\mathrm{H}_{2} \mathrm{O}$. This would include, for example, PAH films, hydrogenated amorphous carbon (HAC) and other carbonaceous materials. There may, however, be differences in the agglomeration where the diffusion barrier of $\mathrm{H}_{2} \mathrm{O}$ over the substrate are significantly larger than that we have measured. Although, this does not take account of reaction-enthalpy release during $\mathrm{H}_{2} \mathrm{O}$ formation promoting "hot molecule" behaviour on the surface. As $\mathrm{H}_{2} \mathrm{O}$ slowly aggregates to form icy mountains, patches of the siliceous and carbonaceous grain surface are left exposed. It follows that both the freeze-out of gas-phase formed molecules, like CO, and the reactive accretion starting from adsorbed atomic species occur on a surface that is chemically inhomogeneous, displaying a variety of possible adsorption energies. However, when these substrates are covered by a sufficient number of layers of $\mathrm{H}_{2} \mathrm{O}$ to decouple the $\mathrm{H}_{2} \mathrm{O}$ solid surface from that of the substrate, a few nm at most, the surface processing will be dominated by the surface behaviour of the $\mathrm{H}_{2} \mathrm{O}$ ice.

2. Towards the inner core of molecular clouds, where the temperature is the lowest, nonthermal processes play an important role in changing the icy structure and composition. In particular, the experimental findings for PSD and EPD have been reviewed and reported, respectively. Perhaps the most noteworthy conclusion is that, regardless of the type of energetic processing at play, the non-thermal desorption mechanisms can be complex because what desorbs is not necessarily what was directly excited to begin with. This implies that the energetic conditions required for the initial excitation to occur depend on the chemical nature of the substrate. The intermolecular interactions are also extremely important in efficiently transferring this excitation to the upper layer and hence, to the adsorbate at the vacuum interface that will be ejected into the 
gas phase.

3. Interestingly, $\mathrm{CH}_{3} \mathrm{OH}$, an organic compound, displays a low photodesorption yield as an intact molecule and is found to be considerably less efficient with respect to $\mathrm{H}_{2} \mathrm{O}$ in transferring the initial excitation across the ice during EPD experiments. By contrast, chemical reactivity (e.g. EIC) over physical processes is favoured. This means that in those parts of the interstellar ices where the mantle is C-rich, energetic processing results in the formation of radicals, COMs, and dehydrogenated residues that might become increasingly unsaturated while returning $\mathrm{H}_{2}$ to the gas phase. It is important to stress that this process can be competitive with the hydrogenation of the adsorbed species due to $\mathrm{H}$ atom addition from the gas phase.

4. Finally, on the basis of several assumptions as discussed in the text above, a simple model exploring $\mathrm{CO}$ adsorption and the evolution of $\mathrm{CO}$ surface coverage on top of an icy grain with surfaces of both $\mathrm{ASW}$ and $\mathrm{aSiO}_{2}$ was constructed. Despite the approximate approach in our simulation, the results highlight how CO binds predominantly to one of the two surfaces depending on the temperature and on the efficiency of the non-thermal desorption for the two possible substrates.

For clarity, we propose a simple cartoon (Figure 11) picturing the main processes so far discussed: agglomeration of water, PSD and EPD of small molecules, EIC leading to dehydrogenation of organic molecules and $\mathrm{H}_{2}$ formation.

We would like to conclude by highlighting the key concept underpinning this work: the importance of intermolecular interactions whether these are established between the grain surface (e.g. $\left.\mathrm{aSiO}_{2}\right)$ and the adsorbate (e.g. CO) or between two different species (e.g. CO and $\mathrm{H}_{2} \mathrm{O}$ ). Molecular interactions drive the icy mantle accretion and its chemical evolution by affecting the photochemistry, stabilizing charged species ${ }^{72,73}$ and transferring the excitation to the vacuum interface. Future laboratory experiments are encouraged to test the 


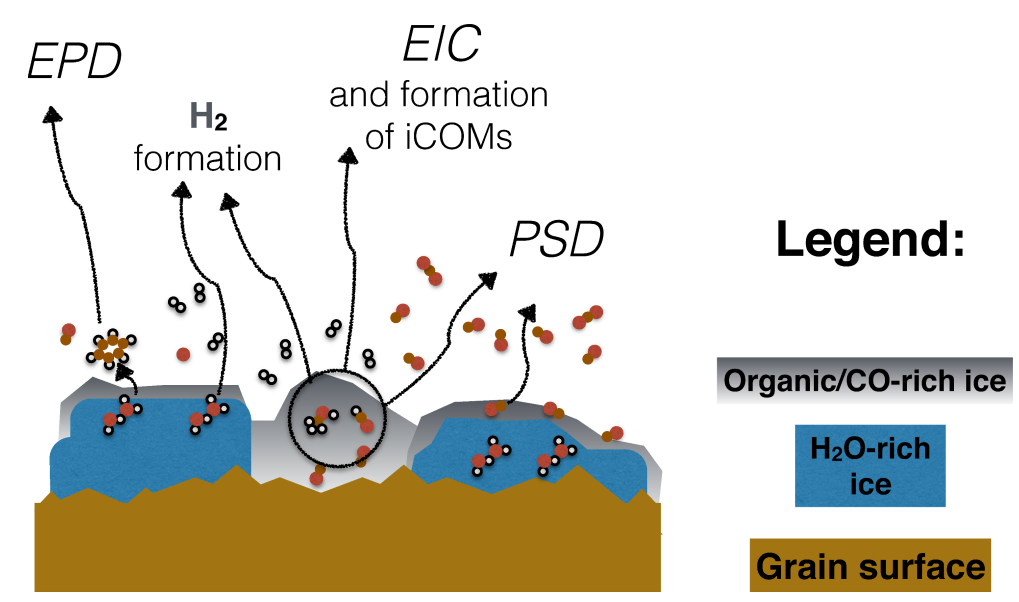

Figure 11: Cartoon showing: formation of water rich areas versus organic and $\mathrm{CO}$ rich regions on top of the grain core; EPD of small molecules adsorbed on ASW, PSD of small molecules such as $\mathrm{CO}$ and $\mathrm{CO}_{2}$ on top from $\mathrm{CO}$ rich ices (2-3 layers are required for the DIET mechanism); dehydrogenation of organic molecules (EIC) leading to $\mathrm{H}_{2}$ formation. $\mathrm{H}_{2}$ release has been observed also in the electron irradiation experiments of water ices, and hence here represented as well.

assumptions made in this work and investigate the dynamics of the discussed processes by measuring the branching ratios and the partition of the energy into translational, vibrational and rotational energy for each desorption channel in play.

\section{Acknowledgement}

The authors acknowledge the support of the UK Science and Technology Facilities Council (STFC, ST/M001075/1), the UK Engineering and Physical Science Research Council (EPSRC, EP/D506158/1) and the European Community FP7-ITN Marie-Curie Programme (LASSIE project, grant agreement \#238258). AGMA thanks the Libyan Government for a scholarship. ARF thanks HWU for a James Watt Scholarship. Financial support from Heriot-Watt University for a number of upgrades to the UHV system is also acknowledged. DM thanks Ms. Elaine Bramwell, an undergraduate project student, for her help in setting up the experimental apparatus. The authors thank the anonymous referees for their comments through which improvements to the manuscript were made. 


\section{References}

(1) van Dishoeck, E. F.; Herbst, E.; Neufeld, D. A. Interstellar water chemistry: from laboratory to observations. Chem. Rev. 2013, 113, 9043-9085.

(2) van Dishoeck, E. F. et al. Water in Star-forming Regions with the Herschel Space Observatory (WISH). I. Overview of Key Program and First Results. Publ. Astron. Soc. Pac. 2011, 123, 138-170.

(3) Cuppen, H. M.; Ioppolo, S.; Romanzin, C.; Linnartz, H. Water formation at low temperatures by surface $\mathrm{O}_{2}$ hydrogenation II: the reaction network. Phys. Chem. Chem. Phys. 2010, 12, 12077-12088.

(4) Lamberts, T.; Cuppen, H. M.; Ioppolo, S.; Linnartz, H. Water formation at low temperatures by surface $\mathrm{O}_{2}$ hydrogenation III: Monte Carlo simulation. Phys. Chem. Chem. Phys. 2013, 15, 8287-8302.

(5) Dulieu, F.; Congiu, E.; Noble, J.; Baouche, S.; Chaabouni, H.; Moudens, A.; Minissale, M.; Cazaux, S. a. How micron-sized dust particles determine the chemistry of our Universe. Sci. Rep. 2013, 3, 1338.

(6) Fraser, H. J.; Collings, M. P.; McCoustra, M. R. S.; Williams, D. A. Thermal desorption of water ice in the interstellar medium. Mon. Not. R. Astron. Soc. 2001, 327, $1165-1172$.

(7) Haynes, D. R.; Tro, N. J.; George, S. M. Condensation and evaporation of water on ice surfaces. J. Phys. Chem. 1992, 96, 8502-8509.

(8) Speedy, R. J.; Debenedetti, P. G.; Smith, R. S.; Huang, C.; Kay, B. D. The evaporation rate, free energy, and entropy of amorphous water at 150 K. J. Chem. Phys. 1996, 105, 240-244. 
(9) Allamandola, L. J.; Bernstein, M. P.; Sandford, S. A.; Walker, R. L. Evolution of Interstellar Ices. Composition and origin of cometary materials. Dordrecht, 1999; pp $219-232$.

(10) Ehrenfreund, P.; Boogert, A.; Gerakines, P.; Tielens, A. Apolar ices. Faraday Discuss. 1998, 109, 463-474.

(11) Garrod, R. T. Three-dimensional, off-lattice Monte Carlo kinetics simulations of interstellar grain chemistry and ice structure. Astrophys. J. 2013, 778, 158.

(12) Clements, A. R.; Berk, B.; Cooke, I. R.; Garrod, R. T. Kinetic Monte Carlo simulations of water ice porosity: extrapolations of deposition parameters from the laboratory to interstellar space. Phys. Chem. Chem. Phys. 2018, 20, 5553-5568.

(13) Vasyunin, A. I.; Herbst, E. A unified Monte Carlo treatment of gas-grain chemistry for large reaction networks. II. A multiphase gas-surface-layered bulk model. Astrophys. J. 2012, 762, 86.

(14) Karssemeijer, L. J.; Ioppolo, S.; van Hemert, M. C.; van der Avoird, A.; Allodi, M. A.; Blake, G. A.; Cuppen, H. M. Dynamics of CO in amorphous water-ice environments. Astrophys. J. 2014, 781, 16.

(15) Noble, J. A.; Congiu, E.; Dulieu, F.; Fraser, H. J. Thermal desorption characteristics of $\mathrm{CO}, \mathrm{O}_{2}$ and $\mathrm{CO}_{2}$ on non-porous water, crystalline water and silicate surfaces at submonolayer and multilayer coverages. Mon. Not. R. Astron. Soc. 2012, 421, 768779.

(16) Raut, U.; Famá, M.; Teolis, B. D.; Baragiola, R. A. Characterization of porosity in vapor-deposited amorphous solid water from methane adsorption. J. Chem. Phys. 2007, 127, 204713. 
(17) He, J.; Acharyya, K.; Vidali, G. Binding energy of molecules on water ice: laboratory. 2016, 825, 89.

(18) He, J.; Acharyya, K.; Vidali, G. Sticking of molecules on nonporous amorphous water ice. Astrophys. J. 2016, 823, 56.

(19) He, J.; Shi, J.; Hopkins, T.; Vidali, G.; Kaufman, M. J. A new determination of the binding energy of atomic oxygen on dust grain surfaces: experimental results and simulations. Astrophys. J. 2015, 801, 120.

(20) Lauck, T.; Karssemeijer, L.; Shulenberger, K.; Rajappan, M.; Öberg, K. I.; Cuppen, H. M. CO diffusion into amorphous $\mathrm{H}_{2} \mathrm{O}$ ices. Astrophys. J. 2015, 801, 118.

(21) Cooke, I. R.; Öberg, K. I.; Fayolle, E. C.; Peeler, Z.; Bergner, J. B. CO diffusion and desorption kinetics in $\mathrm{CO}_{2}$ ices. Astrophys. J. 2018, 852, 75.

(22) Cuppen, H. M.; Herbst, E. Simulation of the formation and morphology of ice mantles on interstellar grains. Astrophys. J. 2007, 668, 294-309.

(23) Noble, J. A.; Diana, S.; Dulieu, F. Segregation of $\mathrm{O}_{2}$ and CO on the surface of dust grains determines the desorption energy of $\mathrm{O}_{2}$. Mon. Not. R. Astron. Soc. 2015, 454, $2636-2646$.

(24) Nguyen, T.; Baouche, S.; Congiu, E.; Diana, S.; Pagani, L.; Dulieu, F. Segregation effect and $\mathrm{N}_{2}$ binding energy reduction in CO- $\mathrm{N}_{2}$ systems adsorbed on water ice substrates. Astron. Astrophys. 2018, 619, A111.

(25) Thrower, J. D.; Collings, M. P.; Rutten, F. J. M.; McCoustra, M. R. S. Laboratory investigations of the interaction between benzene and bare silicate grain surfaces. Mon. Not. R. Astron. Soc. 2009, 394, 1510-1518.

(26) Fraser, H. J.; Collings, M. P.; McCoustra, M. R. S. Laboratory surface astrophysics experiment. Rev. Sci. Instrum. 2002, 73, 2161-2170. 
(27) Frankland, V. L.; Rosu-Finsen, A.; Lasne, J.; Collings, M. P.; McCoustra, M. R. S. Laboratory surface astrochemistry experiments. Re. Sci. Instrum. 2015, 86, 055103.

(28) Marchione, D.; Thrower, J. D.; McCoustra, M. R. S. Efficient electron-promoted desorption of benzene from water ice surfaces. Phys. Chem. Chem. Phys. 2016, 18, 40264034 .

(29) Marchione, D.; McCoustra, M. R. S. Electrons, excitons and hydrogen bonding: electron-promoted desorption from molecular ice surfaces. Phys. Chem. Chem. Phys. 2016, 18, 29747-29755.

(30) Penteado, E. M.; Walsh, C.; Cuppen, H. M. Sensitivity analysis of grain surface chemistry to binding energies of ice species. Astrophys. J. 2017, 844, 71.

(31) Tait, S. L.; Dohnálek, Z.; Campbell, C. T.; Kay, B. D. n-alkanes on MgO(100). I. Coverage-dependent desorption kinetics of n-butane. The Journal of Chemical Physics 2005, 122, 164707.

(32) Amiaud, L.; Fillion, J. H.; Baouche, S.; Dulieu, F.; Momeni, A.; Lemaire, J. L. Interaction of $\mathrm{D}_{2}$ with $\mathrm{H}_{2} \mathrm{O}$ amorphous ice studied by temperature-programed desorption experiments. J. Chem. Phys 2006, 124, 094702.

(33) Zubkov, T.; Smith, R. S.; Engstrom, T. R.; Kay, B. D. Adsorption, desorption, and diffusion of nitrogen in a model nanoporous material. I. Surface limited desorption kinetics in amorphous solid water. J. Chem. Phys. 2007, 127, 184707.

(34) Suhasaria, T.; Zacharias, H.; Thrower, J. D. Thermal desorption of astrophysically relevant molecules from forsterite(010). Mon. Not. R. Astron. Soc. 2017, 472, 389399.

(35) Thrower, J. D.; Collings, M. P.; Rutten, F. J. M.; McCoustra, M. R. S. Thermal 
desorption of $\mathrm{C}_{6} \mathrm{H}_{6}$ from surfaces of astrophysical relevance. J. Chem. Phys. 2009, 131, 244711.

(36) He, J.; Vidali, G. Application of a diffusion-desorption rate equation model in astrochemistry. Faraday Discuss. 2014, 168, 517-532.

(37) Collings, M. P.; Frankland, V.; Lasne, J.; Marchione, D.; Rosu-Finsen, A.; McCoustra, M. R. S. Probing model interstellar grain surfaces with small molecules. Mon. Not. R. Astron. Soc. 2015, 449, 1826-1833.

(38) Ulbricht, H.; Zacharia, R.; Cindir, N.; Hertel, T. Thermal desorption of gases and solvents from graphite and carbon nanotube surfaces. Carbon 2006, 44, 2931-2942.

(39) Fuchs, G. W.; Acharyya, K.; Bisschop, S. E.; Öberg, K. I.; van Broekhuizen, F. A.; Fraser, H. J.; Schlemmer, S.; van Dishoeck, E. F.; Linnartz, H. Comparative studies of $\mathrm{O}_{2}$ and $\mathrm{N}_{2}$ in pure, mixed and layered CO ices. Faraday Discuss. 2006, 133, 331-345.

(40) Acharyya, K.; Fuchs, G. W.; Fraser, H. J.; van Dishoeck, E. F.; Linnartz, H. Desorption of $\mathrm{CO}$ and $\mathrm{O}_{2}$ interstellar ice analogs. Astron. Astrophys. 2007, 466, 1005-1012.

(41) Smith, R. S.; May, R. A.; Kay, B. D. Desorption kinetics of Ar, Kr, Xe, $\mathrm{N}_{2}, \mathrm{O}_{2}$, CO, methane, ethane, and propane from graphene and amorphous solid water surfaces. $J$. Phys. Chem. B 2016, 120, 1979-1987.

(42) Burke, D. J.; Brown, W. A. Ice in space: surface science investigations of the thermal desorption of model interstellar ices on dust grain analogue surfaces. Phys. Chem. Chem. Phys. 2010, 12, 5947-5969.

(43) Smith, R. S.; Matthiesen, J.; Kay, B. D. Desorption kinetics of methanol, ethanol, and water from graphene. J. Phys. Chem. A 2014, 118, 8242-8250.

(44) Smith, R. S.; Kay, B. D. Desorption kinetics of benzene and cyclohexane from a graphene surface. J. Phys. Chem. B 2018, 122, 587-594. 
(45) Redhead, P. A. Thermal desorption of gases. Vacuum 1962, 12, 203-211.

(46) Taj, S.; Baird, D.; Rosu-Finsen, A.; McCoustra, M. Surface heterogeneity and inhomogeneous broadening of vibrational line profiles. Phys. Chem. Chem. Phys. 2017, 19, 7990-7995.

(47) Haynes, D. R.; Tro, N. J.; George, S. M. Condensation and evaporation of water on ice surfaces. J. Phys. Chem. 1992, 96, 8502-8509.

(48) Rosu-Finsen, A.; Marchione, D.; Salter, T. L.; Stubbing, J. W.; Brown, W. A.; McCoustra, M. R. S. Peeling the astronomical onion. Phys. Chem. Chem. Phys. 2016, $18,31930-31935$.

(49) Buch, V.; Sigurd, B.; Devlin, J. P.; Buck, U.; Kazimirski, J. K. Solid water clusters in the size range of tens-thousands of $\mathrm{H}_{2} \mathrm{O}$ : a combined computational/spectroscopic outlook. Int. Rev. Phys. Chem. 2004, 23, 375-433.

(50) Rosu-Finsen, A.; McCoustra, M. R. S. Impact of oxygen chemistry on model interstellar grain surfaces. Phys. Chem. Chem. Phys. 2018, 20, 5368-5376.

(51) Pontoppidan, K. M.; Fraser, H. J.; Dartois, E.; Thi, W.-F.; van Dishoeck, E. F.; Boogert, A. C. A.; d'Hendecourt, L.; Tielens, A. G. G. M.; Bisschop, S. E. A 3-5 $\mu \mathrm{m}$ VLT spectroscopic survey of embedded young low mass stars I - Structure of the CO ice. Astron. Astrophys. 2003, 408, 981-1007.

(52) Karssemeijer, L. J.; Cuppen, H. M. Diffusion-desorption ratio of adsorbed CO and $\mathrm{CO}_{2}$ on water ice. Astron. Astrophys. 2014, 569, A107.

(53) Linnartz, H.; Ioppolo, S.; Fedoseev, G. Atom addition reactions in interstellar ice analogues. Int. Rev. Phys. Chem. 2015, 34, 205-237.

(54) Watanabe, N.; Nagaoka, A.; Shiraki, T.; Kouchi, A. Hydrogenation of CO on Pure Solid CO and CO- $\mathrm{H}_{2} \mathrm{O}$ Mixed Ice. The Astrophysical Journal 2004, 616, 638-642. 
(55) Marchione, D. Thermal and non-thermal processes of simple molecules on model interstellar ices. Ph.D. thesis, Heriot-Watt University, 2015.

(56) Lasne, J.; Rosu-Finsen, A.; Cassidy, A.; McCoustra, M. R. S.; Field, D. Spontaneous electric fields in solid carbon monoxide. Phys. Chem. Chem. Phys. 2015, 17, 3017730187.

(57) Plekan, O.; Rosu-Finsen, A.; Cassidy, A. M.; Lasne, J.; McCoustra, M. R. S.; Field, D. A review of recent progress in understanding the spontelectric state of matter. Eur. Phys. J. D 2017, 71, 162.

(58) Rosu-Finsen, A.; Lasne, J.; Cassidy, A.; McCoustra, M. R. S.; Field, D. Spontaneous polarization of solid $\mathrm{CO}$ on water ices and some astrophysical implications. Phys. Chem. Chem. Phys. 2016, 18, 5159-5171.

(59) Rosu-Finsen, A.; Lasne, J.; Cassidy, A.; McCoustra, M. R. S.; Field, D. Enabling Star Formation via Spontaneous Molecular Dipole Orientation in Icy Solids. Astrophys. J. 2016, 832, 1.

(60) Öberg, K. I.; Fuchs, G. W.; Awad, Z.; Fraser, H. J.; Schlemmer, S.; van Dishoeck, E. F.; Linnartz, H. Photodesorption of CO Ice. Astrophys. J. 2007, 662, L23-L26.

(61) Öberg, K. I.; Linnartz, H.; Visser, R.; van Dishoeck, E. F. Photodesorption of CO ice. II. $\mathrm{H}_{2} \mathrm{O}$ and $\mathrm{D}_{2} \mathrm{O}$. Astrophys. J. 2009, 693, 1209-1218.

(62) Cuylle, S. H.; Tenenbaum, E. D.; Bouwman, J.; Linnartz, H.; Allamandola, L. J. Ly $\alpha-$ induced charge effects of polycyclic aromatic hydrocarbons embedded in ammonia and ammonia:water ice. Mon. Not. R. Astron. Soc. 2012, 423, 1825-1830.

(63) Cuylle, S. H.; Allamandola, L. J.; Linnartz, H. Photochemistry of PAHs in cosmic water ice - The effect of concentration on UV-VIS spectroscopy and ionization efficiency. Astron. Astrophys. 2014, 562, A22. 
(64) Cuylle, S. H.; Zhao, D.; Strazzulla, G.; Linnartz, H. Vacuum ultraviolet photochemistry of solid acetylene: a multispectral approach. Astron. Astrophys. 2014, 570, A83.

(65) Cook, A. M.; Ricca, A.; Mattioda, A. L.; Bouwman, J.; Roser, J.; Linnartz, H.; Bregman, J.; Allamandola, L. J. Photochemistry of polycyclic aromatic hydrocarbons in cosmic water ice: the role of PAH ionization and concentration. Astrophys. J. 2015, $799,14$.

(66) Fedoseev, G.; Chuang, K.-J.; van Dishoeck, E. F.; Ioppolo, S.; Linnartz, H. Simultaneous hydrogenation and UV-photolysis experiments of NO in CO-rich interstellar ice analogues; linking $\mathrm{HNCO}, \mathrm{OCN}^{-}, \mathrm{NH}_{2} \mathrm{CHO}$, and $\mathrm{NH}_{2} \mathrm{OH}$. Mon. Not. R. Astron. Soc. 2016, 460, 4297-4309.

(67) Ligterink, N. F. W.; Terwisscha van Scheltinga, J.; Taquet, V.; Jørgensen, J. K.; Cazaux, S.; van Dishoeck, E. F.; Linnartz, H. The formation of peptide-like molecules on interstellar dust grains. Mon. Not. R. Astron. Soc. 2018, 480, 3628-3643.

(68) Chuang, K.-J.; Fedoseev, D., G. Qasim; Ioppolo, S.; van Dishoeck, E.; Linnartz, H. Production of complex organic molecules: H-atom addition versus UV irradiation. Mon. Not. R. Astron. Soc. 2017, 467, 2552-2565.

(69) Henderson, B. L.; Gudipati, M. S. Direct detection of complex organic products in ultraviolet (Ly $\alpha)$ and electron-irradiated astrophysical and cometary ice analogs using two-step laser ablation and ionization mass spectrometry. Astrophys. J. 2015, 800, 66.

(70) Gudipati, M. S.; Yang, R. In-situ probing of radiation-induced processing of organics in astrophysical ice analogs - novel laser desorption laser ionization time-of-flight mass spectroscopic studies. Astrophys. J. 2012, 756, L24.

(71) Gudipati, M. S.; Dworkin, J. P.; Chillier, X. D. F.; Allamandola, L. J. Luminescence from vacuum-ultraviolet-irradiated cosmic ice analogs and residues. Astrophys. J. 2003, 583, 514-523. 
(72) Gudipati, M. S.; Allamandola, L. J. Facile generation and storage of polycyclic aromatic hydrocarbon ions in astrophysical ices. Astrophys. J. 2003, 596, L195-L198.

(73) Gudipati, M. S. Matrix-isolation in cryogenic water-ices:âĂL facile generation, storage, and optical spectroscopy of aromatic radical cations. J. Phys. Chem. A 2004, 108, $4412-4419$.

(74) Gudipati, M. S.; Allamandola, L. J. Double ionization of quaterrylene $\left(\mathrm{C}_{40} \mathrm{H}_{20}\right)$ in water-Ice at $20 \mathrm{~K}$ with Ly $\alpha(121.6 \mathrm{~nm})$ radiation. J. Phys. Chem. A 2006, 110, 90209024 .

(75) Shi, J.; Grieves, G. A.; Orlando, T. M. Vacuum ultravioet photon-stimulated oxidation of buried ice: graphite grain interfaces. Astrophys. J. 2015, 804, 24.

(76) Watanabe, N.; Mouri, O.; Nagaoka, A.; Chigai, T.; Kouchi, A.; Pirronello, V. Laboratory simulation of competition between hydrogenation and photolysis in the chemical evolution of $\mathrm{H}_{2} \mathrm{O}-\mathrm{CO}$ ice mixtures. Astrophys. J 2007, 668, 1001-1011.

(77) Cruz-Diaz, G. A.; Martín-Doménech, R.; Muñoz Caro, G. M.; Chen, Y.-J. Negligible photodesorption of methanol ice and active photon-induced desorption of its irradiation products. Astron. Astrophys. 2016, 592, A68.

(78) Martín-Doménech, R.; Cruz-Diaz, G. A.; Muñoz Caro, G. M. UV photoprocessing of $\mathrm{NH}_{3}$ ice: photon-induced desorption mechanisms. Mon. Not. R. Astron. Soc. 2017, 473, 2575-2582.

(79) Yuan, C.; Yates, J. T. Isotope effect in the photochemical decomposition of $\mathrm{CO}_{2}$ (ice) by Lyman- $\alpha$ radiation. J. Chem. Phys. 2013, 138, 154302.

(80) Martín-Doménech, R.; Manzano-Santamaría, J.; Muñoz Caro, G. M.; CruzDíaz, G. A.; Chen, Y.-J.; Herrero, V. J.; Tanarro, I. UV photoprocessing of $\mathrm{CO}_{2}$ ice: a 
complete quantification of photochemistry and photon-induced desorption processes. Astron. Astrophys. 2015, 584, A14.

(81) Bahr, D. A.; Baragiola, R. A. Photodesorption of solid $\mathrm{CO}_{2}$ by Lya. Astrophys. J. 2012, $761,36$.

(82) Chen, Y.-J.; Chuang, K.-J.; Muñoz Caro, G. M.; Nuevo, M.; Chu, C.-C.; Yih, T.S.; Ip, W.-H.; Wu, C.-Y. R. Vacuum ultraviolet emission spectrum measurement of a microwawe-discharge hyhdrogen-flow lamp in several configurations: application to photodesorption of CO ice. Astrophys. J. 2014, 781, 15.

(83) Ligterink, N. F. W.; Paardekooper, D. M.; Chuang, K. J.; Both, M. L.; CruzDiaz, G. A.; van Helden, J. H.; Linnartz, H. Controlling the emission profile of an $\mathrm{H}_{2}$ discharge lamp to simulate interstellar radiation fields. Astron. Astrophys. 2015, $584, \mathrm{~A} 56$.

(84) Muñoz Caro, G. M.; Jiménez-Escobar, A.; Martín-Gago, J. A.; Rogero, C.; Atienza, C.; Puertas, S.; Sobrado, J. M.; Torres-Redondo, J. New results on thermal and photodesorption of CO ice using the novel interStellar astrochemistry chamber (ISAC). Astron. Astrophys. 2010, 522, A108.

(85) Paardekooper, D. M.; Fedoseev, G.; Riedo, A.; Linnartz, H. A novel approach to measure photodesorption rates of interstellar ice analogues - The photodesorption rate of CO ice reinvestigated. Astron. Astrophys. 2016, 596, A72.

(86) Muñoz Caro, G. M.; Chen, Y.-J.; Aparicio, S.; Jiménez-Escobar, A.; Rosu-Finsen, A.; Lasne, J.; McCoustra, M. R. S. Photodesorption and physical properties of CO ice as a function of temperature. Astron. Astrophys. 2016, 589, A19.

(87) Fayolle, E. C.; Bertin, M.; Romanzin, C.; Michaut, X.; Öberg, K. I.; Linnartz, H.; Fillion, J.-H. CO ice photodesorption: a wavelength-dependent study. Astrophys. J. 2011, 739, L36. 
(88) Bertin, M.; Fayolle, E. C.; Romanzin, C.; Öberg, K. I.; Michaut, X.; Moudens, A.; Philippe, L.; Jeseck, P.; Linnartz, H.; Fillion, J.-H. UV photodesorption of interstellar CO ice analogues: from subsurface excitation to surface desorption. Phys. Chem. Chem. Phys. 2012, 14, 9929-9935.

(89) Dupuy, R.; Bertin, M.; Féraud, G.; Michaut, X.; Jeseck, P.; Doronin, M.; Philippe, L.; Romanzin, C.; Fillion, J.-H. Spectrally-resolved UV photodesorption of $\mathrm{CH}_{4}$ in pure and layered ices. Astron. Astrophys. 2017, 603, A61.

(90) Fillion, J.-H.; Fayolle, E. C.; Michaut, X.; Doronin, M.; Philippe, L.; Rakovsky, J.; Romanzin, C.; Champion, N.; ÃÜberg, K. I.; Linnartz, H.; Bertin, M. Wavelength resolved UV photodesorption and photochemistry of $\mathrm{CO}_{2}$ ice. Faraday Discuss. 2014, $168,533-552$.

(91) Bertin, M.; Romanzin, C.; Doronin, M.; Philippe, L.; Jeseck, P.; Ligterink, N.; Linnartz, H.; Michaut, X.; Fillion, J.-H. UV photodesorption of methanol in pure and CO-rich ices: desorption rates of the intact molecule and of the photofragments. Astrophys. J. 2016, 817, L12.

(92) Lu, H.-C.; Chen, H.-K.; Cheng, B.-M.; Kuo, Y.-P.; Ogilvie, J. F. Spectra in the vacuum ultraviolet region of $\mathrm{CO}$ in gaseous and solid phases and dispersed in solid argon at 10 K. J. Phys. B., At. Mol. Opt. 2005, 38, 3693-3704.

(93) Lu, H.-C.; Chen, H.-K.; Cheng, B.-M.; Ogilvie, J. Absorption spectra in the vacuum ultraviolet region of small molecules in condensed phases. Spectrochim. Acta A 2008, 71, 1485-1491.

(94) Fayolle, E. C.; Bertin, M.; Romanzin, C.; M Poderoso, H. A.; Philippe, L.; Michaut, X.; Jeseck, P.; Linnartz, H.; Öberg, K. I.; Fillion, J.-H. Wavelength-dependent UV photodesorption of pure $\mathrm{N}_{2}$ and $\mathrm{O}_{2}$ ices. Astron. Astrophys. 2013, 556, A122. 
(95) Chakarov, D. V.; Gleeson, M. A.; Kasemo, B. Photoreactions of water and carbon at 90 K. J. Chem. Phys. 2001, 115, 9477-9483.

(96) Bergeld, J.; Kasemo, B.; Chakarov, D. Photocatalytic reactions at the graphite/ice interface. Phys. Chem. Chem. Phys. 2008, 10, 1151-1155.

(97) van Hemert, M. C.; Takahashi, J.; van Dishoeck, E. F. Molecular dynamics study of the photodesorption of CO ice. The Journal of Physical Chemistry A 2015, 119, 6354-6369.

(98) Arnolds, H.; Rehbein, C.; Roberts, G.; Levis, R. J.; King, D. A. Femtosecond nearinfrared laser desorption of multilayer benzene on $\operatorname{Pt}\{111\}$ : a molecular newton's cradle? J. Phys. Chem. B 2000, 104, 3375-3382.

(99) Thrower, J. D.; Burke, D. J.; Collings, M. P.; Dawes, A.; Holtom, P. D.; Jamme, F.; Kendall, P.; Brown, W. A.; Clark, I. P.; Fraser, H. J.; McCoustra, M. r. S.; Mason, N. J.; Parker, A. W. Desorption of hot molecules from photon irradiated interstellar ices. Astrophys. J. 2008, 673, 1233-1239.

(100) Thrower, J. D.; Abdulgalil, A. G. M.; Collings, M. P.; McCoustra, M. R. S.; Burke, D. J.; Brown, W. A.; Dawes, A.; Holtom, P. J.; Kendall, P.; Mason, N. J.; Jamme, F.; Fraser, H. J.; Rutten, F. J. M. Photon- and electron-stimulated desorption from laboratory models of interstellar ice grains. J. Vac. Sci. Technol. A 2010, 28, 799-806.

(101) Yabushita, A.; Hama, T.; Iida, D.; Kawanaka, N.; Kawasaki, M.; Watanabe, N.; Ashfold, M. N. R.; Loock, H.-P. Measurements of energy partitioning in $\mathrm{H}_{2}$ formation by photolysis of amorphous water ice. Astrophys. J. 2008, 682, L69-L72.

(102) Yabushita, k.; Hama, T.; Yokoyama, M.; Kawasaki, M.; Andersson, S.; Dixon, R. N.; Ashfold, M. N. R.; Watanabe, N. Translational and rotational energy measurements 
of photodesorbed water molecules in their vibrational ground state from amorphous solid water. Astrophys. J. 2009, 699, L80-L83.

(103) Heays, A. N.; Bosman, A. D.; van Dishoeck, E. F. Photodissociation and photoionisation of atoms and molecules of astrophysical interest. Astron. Astrophys. 2017, 602, A105.

(104) Öberg, K. I. Photochemistry and astrochemistry: photochemical pathways to interstellar complex organic molecules. Chem. Rev. 2016, 116, 9631-9663.

(105) Thrower, J. D.; Collings, M. P.; Rutten, F. J. M.; McCoustra, M. R. S. Highly efficient electron-stimulated desorption of benzene from amorphous solid water ice. Chem. Phys. Lett. 2011, 505, 106-111.

(106) Marchione, D.; McCoustra, M. R. S. Non-covalent interaction of benzene with methanol and diethyl ether solid surfaces. Phys. Chem. Chem. Phys. 2016, 18, 2079020801.

(107) Gotch, A. J.; Garrett, A. W.; Severance, D. L.; Zwier, T. S. The structure and photophysics of clusters of immiscible liquids: $\mathrm{C}_{6} \mathrm{H}_{6}\left(\mathrm{H}_{2} \mathrm{O}\right)_{n}$. Chem. Phys. Lett. 1991, 178, $121-129$.

(108) Gotch, A. J.; Zwier, T. S. Multiphoton ionization studies of clusters of immiscible liquids. I. $\mathrm{C}_{6} \mathrm{H}_{6}-\left(\mathrm{H}_{2} \mathrm{O}\right)_{n}, \mathrm{n}=1,2$. J. Chem. Phys. 1992, 96, 3388-3401.

(109) Garrett, A. W.; Zwier, T. S. Multiphoton ionization studies of clusters of immiscible liquids. II. $\mathrm{C}_{6} \mathrm{H}_{6}-\left(\mathrm{H}_{2} \mathrm{O}\right)_{n}, \mathrm{n}=3-8$ and $\left(\mathrm{C}_{6} \mathrm{H}_{6}\right)_{2^{-}}\left(\mathrm{H}_{2} \mathrm{O}\right)_{1,2}$. J. Chem. Phys. 1992, 96, $3402-3410$.

(110) Pribble, R. N.; Zwier, T. S. Probing hydrogen bonding in benzene-(water) clusters using resonant ion-dip IR spectroscopy. Faraday Discuss. 1994, 97, 229-241. 
(111) Sharma, D.; Paterson, M. J. The structure and UV spectroscopy of benzene-water (BzW6) clusters using time-dependent density functional theory. Photochem. Photobiol. Sci. 2014, 13, 1549-1560.

(112) Slipchenko, L. V.; Gordon, M. S. Water-benzene interactions: an effective fragment potential and correlated quantum chemistry study. J. Phys. Chem. A 2009, 113, 2092-2102.

(113) Li, S.; Cooper, V. R.; Thonhauser, T.; Puzder, A.; Langreth, D. C. A density functional theory study of the benzene-water complex. J Phys. Chem. A 2008, 112, 9031-9036.

(114) Veljković, D. Z.; Janjić, G. V.; Zarić, S. D. Are C-H ‥ O interactions linear? The case of aromatic CH donors. CrystEngComm 2011, 13, 5005-5010.

(115) Malenov, D. P.; Janjić, G. V.; Veljković, D. Z.; Zarić, S. D. Mutual influence of parallel, $\mathrm{CH} / \mathrm{O}, \mathrm{OH} / \pi$ and lone pair/ $\pi$ interactions in water/benzene/water system. Comput. Theor. Chem. 2013, 1018, 59-65.

(116) Kimmel, G. A.; Orlando, T. M.; Vézina, C.; Sanche, L. Low-energy electron-stimulated production of molecular hydrogen from amorphous water ice. J. Chem. Phys. 1994, $101,3282-3286$.

(117) Otto, A.; Lynch, M. J.; Aust, J. Characteristic electron energy losses of solid benzene and ice. Aust. J. Phys. 1970, 23, 609-612.

(118) Heller, M.; Hamm, R. N.; Birkhoff, R. D.; Painter, L. R. Collective oscillation in liquid water. J. Chem. Phys. 1974, 60, 3483-3486.

(119) Daniels, J. Bestimmung der optischen konstanten von eis aus energie - verlustmessungen von schnellen elektronen. Opt. Commun. 1971, 3, 240-243.

(120) LaVerne, J. A.; Mozumder, A. Concerning plasmon excitation in liquid water. Radiat. Res. 1993, 133, 282-288. 
(121) Wilson, C. D.; Dukes, C. A.; Baragiola, R. A. Search for the plasmon in condensed water. Phys. Rev. B 2001, 63, 121101.

(122) Leapman, R. D.; Sun, S. Cryo-electron energy loss spectroscopy: observations on vitrified hydrated specimens and radiation damage. Ultramicroscopy 1995, 59, 71 - 79, Proceedings of the 2nd international workshop on Electron Energy Loss Spectroscopy and Imaging.

(123) Kobayashi, K. Optical spectra and electronic structure of ice. J. Phys. Chem. 1983, $87,4317-4321$.

(124) Shen, C. J.; Greenberg, J. M.; Schutte, W. A.; van Dishoeck, E. F. Cosmic ray induced explosive chemical desorption in dense clouds. Astron. Astrophys. 2004, 415, 203-215.

(125) Pimblott, S. M.; LaVerne, J. A. Production of low-energy electrons by ionizing radiation. Rad. Phys. and Chem. 2007, 76, $1244-1247$, Proceedings of the 11th Tihany Symposium on Radiation Chemistry.

(126) Garrett, B. C. et al. Role of water in electron-initiated processes and radical chemistry: issues and scientific advances. Chem. Rev. 2005, 105, 355-390.

(127) Shingledecker, C. N.; Herbst, E. A general method for the inclusion of radiation chemistry in astrochemical models. Phys. Chem. Chem. Phys. 2018, 20, 5359-5367.

(128) Cernicharo, J.; Heras, A. M.; Tielens, A. G. G. M.; Pardo, J. R.; Herpin, F.; Guélin, M.; Waters, L. B. F. M. Infrared space observatory's discovery of $\mathrm{C}_{4} \mathrm{H}_{2}, \mathrm{C}_{6} \mathrm{H}_{2}$, and benzene in CRL 618. Astrophys. J. 2001, 546, L123-L126.

(129) McGuire, B. A.; Burkhardt, A. M.; Kalenskii, S.; Shingledecker, C. N.; Remijan, A. J.; Herbst, E.; McCarthy, M. C. Detection of the aromatic molecule benzonitrile (c$\left.\mathrm{C}_{6} \mathrm{H}_{5} \mathrm{CN}\right)$ in the interstellar medium. Science 2018, 359, 202-205. 
(130) Abdulgalil, A. G. M.; Marchione, D.; Rosu-Finsen, A.; Collings, M. P.; McCoustra, M. R. S. Laboratory investigations of irradiated acetonitrile-containing ices on an interstellar dust analog. J. Vac. Sci. Technol. A 2012, 30, 041505.

(131) Rothard, H.; Ding, J.; Boduch, P.; Andrade, D. P. P.; de Barros, A. L. F.; da Silveira, E. F. Acetone degradation by cosmic rays in the solar neighbourhood and in the Galactic Centre. Mon. Not. R. Astron. Soc. 2014, 444, 3792-3801.

(132) Bordalo, V.; da Silveira, E. F.; Lv, X. Y.; Domaracka, A.; Rothard, H.; Seperuelo Duarte, E.; Boduch, P. Chemical processing of pure ammonia and ammonia-water ices induced by heavy ions. Astrophys. J. 2013, 7744, 105.

(133) Pilling, D. P. P., S. Andrade; da Silveira, E. F.; Rothard, H.; Domaracka, A.; Boduch, P. Formation of unsaturated hydrocarbons in interstellar ice analogues by cosmic rays. Mon. Not. R. Astron. Soc. 2012, 423, 2209-2221.

(134) Boduch, P.; Brunetto, R.; Ding, J. J.; Domaracka, A.; Kaňuchová, Z.; Palumbo, M. E.; Rothard, H.; Strazzulla, G. Ion processing of ices and the origin of $\mathrm{SO}_{2}$ and $\mathrm{O}_{3}$ on the icy surfaces of the icy jovian satellites. Icarus 2016, 277, 424-432.

(135) Mennella, V.; Palumbo, M. E.; Baratta, G. A. Formation of $\mathrm{CO}$ and $\mathrm{CO}_{2}$ molecules by ion irradiation of water ice-covered hydrogenated carbon grains. Astrophys. J. 2004, 615, 1073-1080.

(136) Kaňuchová, Z.; Boduch, P.; Domaracka, A.; Palumbo, M. E.; Rothard, H.; Strazzulla, G. Thermal and energetic processing of astrophysical ice analogues rich in $\mathrm{SO}_{2}$. Astron. Astrophys. 2017, 604, A68.

(137) Petrik, N. G.; Kimmel, G. A. Electron-stimulated reactions in nanoscale water films adsorbed on $\alpha-\mathrm{Al}_{2} \mathrm{O}_{3}(0001)$. Phys. Chem. Chem. Phys. 2018, 20, 11634-11642. 
(138) Ribeiro, F. d. A.; Almeida, G. C.; Garcia-Basabe, Y.; Wolff, W.; BoechatRoberty, H. M.; Rocco, M. L. M. Non-thermal ion desorption from an acetonitrile $\left(\mathrm{CH}_{3} \mathrm{CN}\right)$ astrophysical ice analogue studied by electron stimulated ion desorption. Phys. Chem. Chem. Phys. 2015, 17, 27473-27480.

(139) Yao, Y.; Giapis, K. P. Dynamic molecular oxygen production in cometary comae. Nat. Commun. 2017, 8, 15298.

(140) Yao, Y.; Giapis, K. P. Intramolecular water-splitting reaction in single collisions of water ions with surfaces. Chem. Sci. 2017, 8, 2852-2858.

(141) Abdulgalil, A. G. M.; Marchione, D.; Thrower, J. D.; Collings, M. P.; McCoustra, M. R. S.; Islam, F.; Palumbo, M. E.; Congiu, E.; Dulieu, F. Laboratory studies of electron and ion irradiation of solid acetonitrile $\left(\mathrm{CH}_{3} \mathrm{CN}\right)$. Phil. Trans. R. Soc. A 2013, 371, 20110586.

(142) Marchione, D.; McCoustra, M. R. S. Electron-induced chemistry: preliminary comparative studies of hydrogen production from water, methanol, and diethyl ether. $A C S$ Earth Space Chem. 2017, 1, 310-315.

(143) Mullikin, E. et al. Condensed-phase photochemistry in the absence of radiation chemistry. ACS Earth Space Chem. 2018, 2, 863-868.

(144) Dupuy, R.; Bertin, M.; Féraud, G.; Hassenfratz, M.; Michaut, X.; Putaud, T.; Philippe, L.; Jeseck, P.; Angelucci, M.; Cimino, R.; Baglin, V.; Romanzin, C.; Fillion, J.-H. X-ray photodesorption from water ice in protoplanetary disks and X-raydominated regions. Nat. Astron. 2018, 2, 796-801.

(145) Freeman, G. R. Radiolysis of cyclohexane. I. Pure liquid cyclohexane and cyclohexanebenzene solutions. J. Chem. Phys. 1960, 33, 71-78. 
(146) Ramaradhya, J. M.; Freeman, G. R. Radiolysis of cyclohexane. III. Vapor phase. J. Chem. Phys. 1961, 34, 1726-1729.

(147) Gadallah, K. A. K.; Marchione, D.; Koehler, S. P. K.; McCoustra, M. R. S. Molecular hydrogen production from amorphous solid water during low energy electron irradiation. Phys. Chem. Chem. Phys. 2017, 19, 3349-3357.

(148) Bennett, C. J.; Jamieson, C. S.; Osamura, Y.; Kaiser, R. I. Laboratory studies on the irradiation of methane in interstellar, cometary, and solar system ices. Astrophys. J. 2006, 653, 792-811.

(149) Kaiser, R. I.; Maity, S.; Jones, B. M. Infrared and reflectron time-of-flight mass spectroscopic analysis of methane $\left(\mathrm{CH}_{4}\right)$-carbon monoxide $(\mathrm{CO})$ ices exposed to ionization radiation - toward the formation of carbonyl-bearing molecules in extraterrestrial ices. Phys. Chem. Chem. Phys. 2014, 16, 3399-3424.

(150) Cruz-Diaz, G. A.; Muñoz Caro, G. M.; Chen, Y.-J.; Yih, T.-S. Vacuum-UV spectroscopy of interstellar ice analogs - I. Absorption cross-sections of polar-ice molecules. Astron. Astrophys. 2014, 562, A119.

(151) Prasad, S.; Tarafdar, S. UV radiation field inside dense clouds: its possible existence and chemical implications. Astrophys. J.; (United States) 1983, 267, 603-609.

(152) Fayolle, E. C.; Balfe, J.; Loomis, R.; Bergner, J.; Graninger, D.; Rajappan, M.; Öberg, K. I. $\mathrm{N}_{2}$ and $\mathrm{CO}$ desorption energies from water ice. Astrophys. J. 2016, 816, L28. 


\section{Graphical TOC Entry}

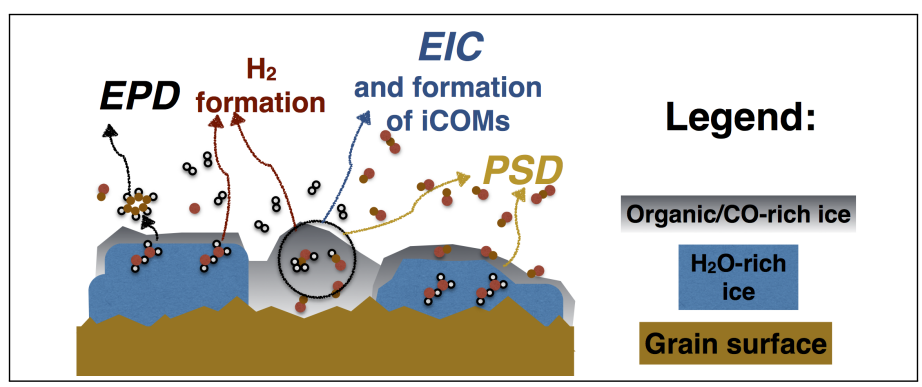




\section{$\mathrm{H}_{2}$}

EPD formation and formation

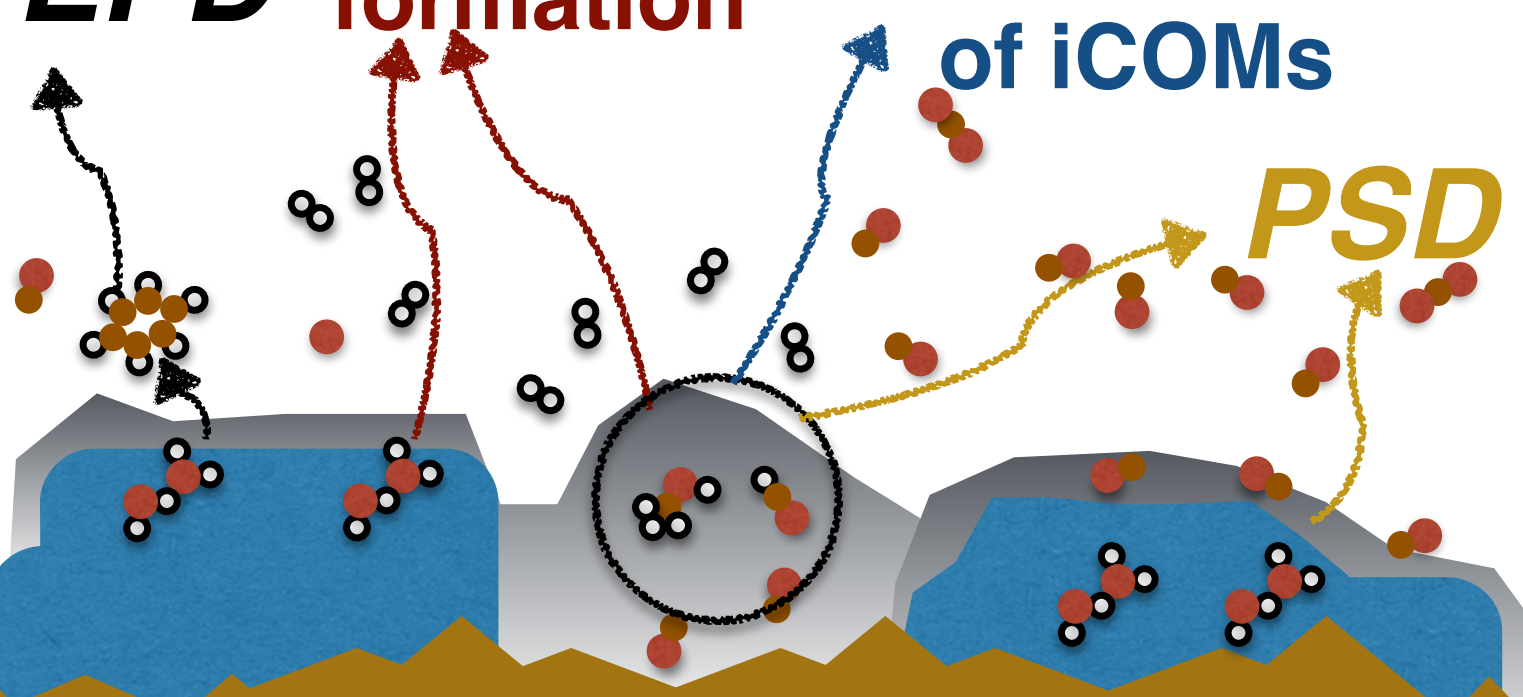

\section{Legend:}

Organic/CO-rich ice

$\mathrm{H}_{2} \mathrm{O}$-rich ice

Grain surface 